\title{
DINÂMICA DE REFLORESTAMENTO EM ÁREAS DE RESTAURAÇÃO APÓS MINERAÇÃO EM UNIDADE DE CONSERVAÇÃO NA AMAZÔNIA ${ }^{1}$
}

\author{
Rafael Paiva Salomão², Sílvio Brienza Júnior ${ }^{3}$ e Nélson Araújo Rosa ${ }^{4}$
}

\begin{abstract}
RESUMO - Objetivou-se neste trabalho avaliar a densidade de plantio, a mortalidade e o incremento periódico anual (IPA) do crescimento em diâmetro e em altura das espécies empregadas no reflorestamento de áreas de restauração florestal, após a lavra de minério em unidade de conservação na Amazônia. Foram também analisadas as práticas edáficas nas áreas de plantio. O monitoramento abrangeu um período de 13 anos (1996 a 2009), na Floresta Nacional de Saracá Taquera, em Porto Trombetas, PA. As espécies foram distribuídas em classes de mortalidade e de incrementos em diâmetro e em altura. Foi analisada a aptidão ecológica baseada na mortalidade e nos incrementos do crescimento, em diâmetro e em altura, das espécies do ecossistema artificial sob restauração. O incremento periódico anual do diâmetro foi classificado como de graus ótimo, alto, baixo e muito baixo, envolvendo, respectivamente, 7, 17, 44 e 1 espécies. Analogamente, quanto à altura, foram classificadas 7, 33, 20 e 9 espécies, respectivamente. A aptidão ecológica das 69 espécies presentes, durante os 13 anos do monitoramento, identificou 24 espécies classificadas como inaptas, 21 como de baixa, 25 como regular, 16 como boa e apenas três como de ótima adaptabilidade. As práticas de caráter edáfico devem ser revistas, por apresentar indícios de estarem influenciando fortemente a mortalidade e desenvolvimento das árvores plantadas nas áreas de restauração.
\end{abstract}

Palavras-chave: Crescimento em diâmetro e altura; Mortalidade de árvores; Restauração de área minerada.

\section{REFORESTATION DYNAMICS IN AREAS OF RESTORATION AFTER MINING IN UNIT OF FOREST CONSERVATION IN THE AMAZON}

\begin{abstract}
The objective of this paper was to evaluate density of planting, of mortality and annual periodic increment (API) of growth in diameter and height of species used in reforestation in areas of forest restoration after mining in conservation units in Amazonia. It was also analyzed the soil management practices in plantation areas. The monitoring covered a period of 13 years (1996-2009), at the National Forest Saracá Taquera, in Porto Trombetas, Pará State, Brazil. The species were distributed in classes of mortality. We analyzed the size and the ecological suitability, based on mortality and growth increments (diameter and height) of the species in the artificial ecosystem restored. The annual periodic increment of diameter considering the studied species allowed the following classification: excellent (7 species), high (33), low (20) and very low (9) and similarly, the grow of tree height it was found: excellent (9 species), superior (20), low (31) and very low (9). The ecological aptitude of 69 species in the study area, based on mortality and the increments in diameter and height, allowed the identification of the following groups of species aptitude: excellent (3), good (16), regular (25), low (21); improper (20) and inept (5). The use of soil practices during the activities of restoration should be reviewed due to strong evidence of mortality and growing of planted trees being influenced by soil storage time, the amount of top soil spread superficially, the acidity and fertility of soil and the top soil depth and the distance of transport to the target areas.
\end{abstract}

Keywords: Height and diameter growth; Tree mortality; Restoration of mined area.

\footnotetext{
${ }^{1}$ Recebido em 05.09.2012 aceito para publicação em 27.11.2013.

${ }^{2}$ Coordenadoria de Botânica do Museu Paraense Emílio Goeldi. E-mail: <salomao@museu-goeldi.br>

${ }^{3}$ Empresa Brasileira de Pesquisa Agropecuária, Centro de Pesquisa Agroflorestal da Amazônia Oriental, Floresta. E-mail:< brienza@cpatu.embrapa.br>

${ }^{4}$ Museu Paraense Emílio Goeldi. E-mail: <nelson.araujo.rosa@gamil.com>
} 


\section{INTRODUÇÃO}

No final da década de 1970, a Mineração Rio do Norte (MRN) iniciou as operações de lavra de bauxita na Floresta Nacional (FLONA) de Saracá Taquera, onde as reservas minerais foram estimadas em 800 milhões de toneladas, distribuídas nos 23 platôs da Flona (LAPA, 2000). As etapas da lavra abrangem, entre outras, a supressão (corte raso) da floresta ombrófila densa, a extração do minério e a posterior recuperação das áreas degradadas pela mineração, de acordo com o Programa de Recuperação de Áreas Degradadas (PRAD) do empreendimento.

Após a lavra, inicia-se o processo de restauração florestal, por meio do reflorestamento heterogêneo, concomitantemente com a incorporação de solo superficial (top soil, terra-preta, solo orgânico), com seu rico banco de sementes e elevado teor de matéria orgânica. Os trabalhos de restauração florestal começaram a ser executados a partir de 1981, sendo, em 1996, iniciado o monitoramento com os objetivos de diagnosticar e subsidiar os diversos procedimentos de restauração das áreas degradadas e, também, conhecer a dinâmica dos plantios florestais e da regeneração natural das espécies arbóreas nas mesmas áreas dos reflorestamentos. Parcelas permanentes foram instaladas nas áreas anuais de restauração florestal, assim como na floresta primária, com o objetivo de permitir avaliações comparativas da dinâmica dessas florestas primárias com a das áreas restauradas (florestas artificiais).

O crescimento em diâmetro e em altura das espécies empregadas nos reflorestamentos das áreas restauradas após a mineração na Amazônia é muito pouco conhecido. Praticamente inexistem estudos na literatura científica com essa abordagem. Para florestas homogêneas e equiâneas, de acordo com Campos e Leite (2006), há extensa literatura no que diz respeito a modelos de crescimento. Nessas florestas plantadas, o incremento é determinado em função das características médias das variáveis dimensionais, das árvores médias do povoamento e da idade (CHASSOT et al., 2011). No entanto, esses modelos são geralmente simples, pois se aplicam a uma ou algumas poucas espécies, não sendo aplicáveis para as florestas inequiâneas (primárias) com milhares de espécies arbóreas em diferentes idades (VANCLAY, 1994).

Alguns estudos abordando o incremento anual do diâmetro, desenvolvidos na Amazônia, foram apresentados por diversos autores (HEINSDIJK, 1965;
VEILLON et al., 1976; MORAES, 1970; PIRES, 1976; CLARK; CLARK, 1994; OLIVEIRA; SILVA, 1995; CHAMBERS et al., 1998; VIEIRA, 2003; LEÃO et al., 2005; SALOMÃO et al., 2002, 2006; SOUZA et al., 2008). Estudos de crescimento em diâmetro de espécies florestais têm demonstrado especificidades que dependem da espécie, do solo, do clima, da topografia, da composição florística, da exposição à luz, do histórico de uso da terra, da idade da árvore, da qualidade do sítio e das classes de tamanho em diâmetro.

A Missão FAO no Brasil produziu dois relatórios (SUDAM, 1974), analisados por Heinsdijk (1965), que, utilizando os dados referentes às mensurações de mais de 120 mil árvores, concluiu que a árvore média da Floresta Amazônica (árvore teórica), independentemente da espécie, pertencente à classe de diâmetro de 25$35 \mathrm{~cm}$, teria incremento médio anual do diâmetro do tronco de $0,8 \mathrm{~cm} \mathrm{ano}^{-1}$; entre $25-155 \mathrm{~cm}$, de $0,5 \mathrm{~cm}_{\text {ano- }}$ 1; e acima de $155 \mathrm{~cm}$ de DAP de $0,37 \mathrm{~cm} \mathrm{ano}^{-1}$, a idade dessas árvores estaria entre 27 e 418 anos.

Um estudo pioneiro que trata do crescimento de árvores amazônicas de florestas tropicais das terras baixas foi implantado em 1971 por Veillon et al. (1976), na Reserva Florestal de Imataca, na Venezuela. O crescimento médio de todos os indivíduos, de 1971 a 1976, independentemente da classe diamétrica, foi de $0,27 \mathrm{~cm}_{\text {ano }}{ }^{-1}$; na classe de $60-79,9 \mathrm{~cm}$, foi estimado o maior incremento $\left(0,50 \mathrm{~cm} \mathrm{ano}^{-1}\right)$; e na classe de 80 - 99,9 cm, o menor $\left(0,10 \mathrm{~cm}^{2} \mathrm{ano}^{-1}\right)$. Em estudo com árvores emergentes na Costa Rica, Clark e Clark (1994) verificaram taxas de crescimento na faixa de 0,05 - 0,6 cm ano ${ }^{-1}$, sendo as maiores taxas de crescimento observadas na classe de diâmetro de $30-70 \mathrm{~cm}$ e as menores, nas árvores que se encontravam nas classes de diâmetro menor que $30 \mathrm{~cm}$.

Um dos primeiros estudos na Amazônia brasileira para avaliar o crescimento em diâmetro de árvores foi desenvolvido por Moraes (1970), na Área de Pesquisas Ecológicas do Guamá (APEG), do Instituto de Pesquisa e Experimentação Agropecuárias do Norte (IPEAN), atual Embrapa Amazônia Oriental (EMBrAPACPATU), em Belém, Pará. Esse autor avaliou mensalmente, através de dendrômetros, o crescimento de 21 espécies arbóreas, concluindo que 17 espécies apresentaram periodicidade estacional de crescimento do tronco, com as fases de maior crescimento correspondendo à época chuvosa. 
No mais antigo estudo com parcelas permanentes da Amazônia brasileira, na Reserva Mocambo/EMBRAPA, em Belém, PA, Pires (1976) avaliou o crescimento diamétrico referente a 15 anos de três espécies florestais. Concluiu que o crescimento não apresentou direta correlação com a idade e nem com a classe de diâmetro, devido ao fato de que, dependendo da posição de cada indivíduo das espécies na mata, a exposição à luz é desuniforme e, consequentemente, os incrementos também o são.

Em floresta secundária originada após o abandono dos tratos silviculturais de uma plantação de 'seringueira' Hevea brasiliensis (Willd. ex A. Juss.) Müll. Arg. estabelecida por volta de 1945, em Belterra, PA, Oliveira e Silva (1995) avaliaram o crescimento de 81 espécies arbóreas em uma área de 50 ha, concluindo que o incremento médio anual do diâmetro (DAP) foi de 0,4 $\mathrm{cm} \mathrm{ano}^{-1}$. Chambers et al. (1998) estimaram que as taxas de crescimento diamétrico médio de árvores de diferentes idades e classes de tamanho, abatidas na região de Manaus,variaram de 0,1 a 0,6 cm ano-1, e as árvores de maior diâmetro tenderam a apresentar taxas de crescimento médio maior do que as árvores de menor diâmetro.

Nos reflorestamentos heterogêneos das décadas de 1980 e 1990, do platô Saracá, na FLONA de Saracá Taquera, no período entre 1996 e 1998, Salomão et al. (2002) concluíram que o incremento periódico anual foi positivo para todos os reflorestamentos anuais daquelas décadas, e a mortalidade periódica nos reflorestamentos foi inferior a $10 \%$ no período de dois anos. No mesmo local, Salomão et al. (2006) avaliaram o crescimento anual do diâmetro basal médio de 34 espécies originárias dos reflorestamentos nas áreas anuais de restauração, no período de 1996 a 1999, concluindo que o incremento periódico anual médio (IPA) variou de 3,22 cm ano-1 Senna multijuga (Rich.) H.S. Irwin \& Barneby - a $0,16 \mathrm{~cm} \mathrm{ano}^{-1}$ - Clarisia racemosa Ruiz \& Pav. - média de $0,98 \pm 0,74 \mathrm{~cm}^{\mathrm{ano}}{ }^{-1}$.

No banco de germoplasma ex situ da Hidrelétrica de Tucuruí, no Pará, Leão et al. (2005) avaliaram o crescimento em diâmetro de 29 espécies plantadas em 22,6 ha, relatando que no período de 15 anos o incremento médio anual variou de $2,16 \mathrm{~cm} \mathrm{ano}^{-1}$ (Acromia aculeata) a $0,30 \mathrm{~cm}$ ano $^{-1}$ - Theobroma grandiflorum (Willd. ex Spreng.) K. Schum.; média de 0,95 $\pm 0,49 \mathrm{~cm} \mathrm{ano}^{-1}$ para todos os indivíduos.
Em sistemas agroflorestais, em Roraima, Tonini et al. (2005) avaliaram quatro espécies florestais nativas, visando identificar espécies promissoras para o plantio em programas de reflorestamento. Concluíram que o crescimento em diâmetro de "andiroba" Carapa guianensis Aubl., “castanha-do-brasil” Bertholletia excelsa Bonpl., "ipê-roxo” Tabebuia avellanedae Lorentz ex Griseb e “jatobá” Hymenaea courbaril L., aos 7 anos de idade, mostrou-se promissor. Concluíram informando que essas espécies apresentaram incrementos médios anuais em diâmetro maiores que $1,0 \mathrm{~cm}$, sendo superiores aos observados nas mesmas espécies crescendo em florestas naturais.

Apenas nos estudos de Salomão et al. (2002, 2006) as práticas silviculturais do reflorestamento foram semelhantes às deste trabalho. Têm sido incipientes para toda a Amazônia brasileira trabalhos demonstrando o crescimento de espécies arbóreas em áreas mineradas. Nesse contexto, foram apresentados os dados de crescimento de espécies amazônicas em outros ecossistemas.

Partindo da hipótese de que deve existir adaptação gradativa das espécies florestais nos ecossistemas artificiais implantados, via reflorestamentos, após as atividades de mineração, este estudo procurou classificar tais espécies em classes relativas à mortalidade e ao incremento do diâmetro e da altura das árvores, classificando-as em grupos de aptidão de espécies para restauração florestal.

\section{MATERIAL E MÉTODOS}

\subsection{Caracterização da área de estudo}

Os inventários florestais contínuos foram realizados no platô Saracá, com altitude média de 180 m, localizado na FLONA de Saracá Taquera (147’02.56'’ S 56 31'49.00' W), no distrito de Porto Trombetas, Município de Oriximiná, Estado do Pará. Nessa FLONA, existem 23 platôs que têm extensões de terrenos planos ou pouco ondulados, elevados, cortados por vales neles encaixados, com ocorrência de minério no subsolo onde a Mineração Rio do Norte S.A. (MRN) desenvolve um projeto míneroindustrial de bauxita (LAPA, 2000). Esses platôs são bem definidos e têm os topos planos achatados com altitudes entre 150 e 200 m (RADAMBRASIL, 1976).

A FLONA acha-se inserida na Região da Floresta Ombrófila Densa, sub-região dos Baixos Platôs da Amazônia no domínio da Floresta Densa Submontana,

Revista Árvore, Viçosa-MG, v.38, n.1, p.1-24, 2014 
cuja fitofisionomia se refere à floresta localizada, principalmente, nos platôs terciários e terraços antigos e recentes, apresentando-se em dois estratos distintos: um emergente e outro uniforme (RADAMBRASIL, 1976). As principais espécies que caracterizam o estrato emergente são: Dinizia excelsa Ducke ('angelim-pedra’), Bertholletia excelsa ('castanheira') e Cedrelinga catanaeformis Ducke ('cedrorana'). O estrato uniforme é caracterizado por espécies dos gêneros Manilkara Adans. ('maçarandubas'), Protium Burnm. F. ('breus') e Pouteria Aubl. ('abius’).

As florestas dos platôs são caracterizadas como do ecossistema das áreas sedimentares do PréCambriano. A estrutura da floresta é bastante uniforme, composta por árvores de grande porte (grossas e bem altas), com ou sem palmeiras e lianas. Floresta com árvores de altura muitas vezes superiores a $50 \mathrm{~m}$ possui grande número de emergentes, sendo caracterizada sempre por um ou dois estratos dominantes. Não possui estrato arbustivo, e as plantas de baixo porte encontradas são, em sua maior parte, árvores jovens em crescimento, resultantes de matrizes próximas (RADAMBRASIL, 1976).

Na bacia amazônica, os depósitos de bauxita são associados à série Barreiras, do Terciário, constituídos de arenitos, siltitos e, ocasionalmente, conglomerados. As lateritas são encontradas no topo dos platôs fortemente dissecados pela erosão, remanescentes do Peneplano Terciário, que se estendem ao longo do lado Nordeste do rio Amazonas, desde as vizinhanças de Oriximiná até Jardilândia, no rio Jari (LAPA, 2000).

O clima da região é o Af (tropical úmido), de acordo com a classificação climática de Köppen (PELL et al., 2007), com médias anuais de temperatura, precipitação pluviométrica, umidade relativa e insolação de, respectivamente, $26^{\circ} \mathrm{C}, 2.197 \mathrm{~mm}, 81 \%$ e $2.026 \mathrm{~h}$ (INMET, 2012).

Na FLONA, a lavra do minério é feita a céu aberto e em faixas com escavação mecânica dos materiais (estéril e minério). A bauxita encontra-se entre 4 e 10 m de profundidade, em área coberta pela floresta ombrófila densa. Sucintamente, as operações de lavra nas minas de bauxita consistem no desmatamento, decapeamento, extração e transporte do minério e posterior restauração florestal das áreas mineradas. Antes da operação de desmatamento, a empresa tem que proceder à avaliação qualitativa e quantitativa da vegetação florestal para, entre outras atividades, possibilitar o aproveitamento de toda a madeira comercial e a valoração dos produtos florestais não madeireiros (PFNM) e subsidiar as ações de restauração florestal das áreas mineradas e daquelas provenientes da infraestrutura necessária para a produção minerária.

\subsection{Coleta de dados nas unidades amostrais}

O reflorestamento analisado neste trabalho referese ao plantio florestal de 1996, quando foram implantadas 23 parcelas de $25 \mathrm{~m} \mathrm{x} 10 \mathrm{~m}$. O período de monitoramento desse reflorestamento foi de 13 anos, com sete medições plurianuais nos anos 1996/97/98/99/00/08/09. Todos os indivíduos oriundos do plantio florestal foram registrados, plaqueados e identificados e tiveram mensurados o diâmetro e a altura total. Durante os 13 anos, mediu-se sempre o diâmetro ao nível do solo (DAS) de cada indivíduo registrado, pois, tendo o monitoramento iniciado em 1996 (ano 0), o plantio daquele ano apresentava somente mudas com no máximo 50 cm de altura, impossibilitando, consequentemente, a tomada do diâmetro a 1,30 m do solo (DAP). Assim, o diâmetro considerado neste trabalho, quando se consideram o DAS e a mortalidade, abrangeu um período de 13 anos; ao se analisar o DAP, o período foi restringido a 11 anos, com medições em 1998/99/00/06/09. A análise da altura compreendeu um intervalo de 13 anos, com medições/estimações nos anos 1996/00/06/09.

\subsection{Descritores calculados e analisados}

Para o reflorestamento de 1996, foram avaliados os dados de 89 espécies distribuídas em 23 famílias, com número de indivíduos (n) por espécie variando de 1 a 109 nas 23 parcelas permanentes de 0,025 ha. Para o cálculo do incremento periódico anual (IPA): (i) em função do DAS, foram analisados os dados de 69 espécies, cujos indivíduos estavam presentes no ano 0 (1996) e permaneceram vivos até o ano 13 (2009) - período de 13 anos; (ii) em função do DAP, foram analisados os dados de 30 espécies, cujos indivíduos estavam presentes no ano 2 (1998) e permaneceram vivos até o ano 13 (2009) - período de 11 anos; e (iii) para o cálculo do IPA da altura total, os dados de 69 espécies, cujos indivíduos estavam presentes no ano 0 (1996) e permaneceram vivos até o ano 13 (2009) - período de 13 anos.

Para a análise da dinâmica florestal, os parâmetros calculados foram a densidade de plantio, a mortalidade periódica absoluta e relativa, o incremento periódico 
anual (IPA) do diâmetro ao nível do solo ou diâmetro basal (DAS), do diâmetro a 1,30 m do solo (DAP) e da altura total (ALT) dos indivíduos de todas as espécies amostradas. Essas variáveis, com distribuição normal, foram distribuídas em classes, cujas amplitudes foram calculadas em função da média e do desvio-padrão da respectiva variável.

O incremento periódico anual (IPA) refere-se ao crescimento para qualquer período específico, dividido pelo número de anos do período. Neste trabalho, os incrementos da variável em questão (DAS, DAP e ALT) foram calculados somente para aqueles indivíduos da espécie que foram registrados na primeira medição da variável (ano 0) e que continuaram vivos até o enésimo ano (ano $n)$.

A mortalidade periódica referiu-se ao período de 1996 a 2009, perfazendo um total de 13 anos. As classes de mortalidade adotadas foram: (i) muito baixa (1MB): mortalidade relativa abaixo do valor da média (M) subtraído de um valor do desvio-padrão (DP); (ii) baixa (2B): mortalidade relativa abaixo da média e igual ou acima do limite superior da classe muito baixa; (iii) alta (3A): mortalidade relativa igual ou acima da média e igual ou abaixo do limite inferior da classe muito alta; e (iv) muito alta (4MA): mortalidade relativa acima da soma da média mais um desvio-padrão.

O incremento periódico anual do diâmetro ao nível do solo (IPA-DAS), que traduziu o crescimento no período de 13 anos (1996 a 2009), foi analisado através da distribuição dos valores em classes: (i) muito alto (1MA): espécie cujo valor do IPA-DAS se encontrava acima da média do IPA-DAS de todas as espécies somadas a um valor do desvio-padrão dessa média; (ii) alto (2A): espécie cujo valor do IPA-DAS se encontrava no intervalo igual ou superior à média do IPA-DAS de todas as espécies somada a um desvio-padrão dessa média; (iii) baixo (3B): espécie cujo valor do IPA-DAS se encontrava no intervalo entre a média do IPA-DAS de todas as espécies subtraídas de um desvio-padrão dessa média; e (iv) muito baixo (4MB): espécie cujo valor do IPA-DAS se encontrava abaixo da média do IPA-DAS de todas as espécies subtraída de um desviopadrão dessa média. A distribuição em classes do incremento periódico anual do DAP para um período de 11 anos (1998 a 2009) e da altura para um período de 13 anos (1996 a 2009) foi feito de forma análoga ao diâmetro basal (IPA-DAS).
A aptidão para a restauração da espécie foi determinada através da análise conjunta do grau de mortalidade e das médias dos incrementos periódicos anuais do diâmetro basal (DAS) e da altura. Consideraram-se, a priori, as espécies com grau de mortalidade muito alto (superior à soma da média e ao desvio-padrão), no período de 13 anos como inaptas, independentemente do grau dos incrementos periódicos do diâmetro e da altura. Analogamente, as espécies com grau de mortalidade muito baixo (inferior à diferença da média menos o desvio-padrão) foram consideradas aptas e classificadas de acordo com as classes de aptidão adotadas.

As espécies foram agrupadas em quatro classes de aptidão para a restauração florestal: (i) ótima - espécie com mortalidade muito baixa e incremento periódico anual (IPA) do diâmetro basal (DAS) e da altura (ALT) muito alto; (ii) boa - espécie com mortalidade muito baixa, IPA-DAS alto ou baixo e IPA-ALT de qualquer classe; (iii) regular - espécie com mortalidade baixa e IPA-DAS muito alto, alto ou baixo e IPA-ALT alto, baixo ou muito baixo; (iv) baixa - espécie com mortalidade alta e IPA-DAS muito alto, alto ou baixo e IPA-ALT de qualquer classe; e (v) inapta - espécie com mortalidade muito alta e IPA-DAS alto, baixo ou muito baixo e IPAALT baixo ou muito baixo.

\subsection{Método de plantio}

Nas áreas anuais de restauração florestal, na FLONA de Saracá Taquera, o solo superficial (“terra-preta”) foi espalhado no terreno por um trator de esteira D-6. De acordo com informação obtida para realização deste estudo, foram colocados cerca de $1.120 \mathrm{~m}^{3} \mathrm{ha}^{-1}$, equivalente a uma camada com espessura aproximada de 11,2 cm (80 caminhões ha-1 com capacidade de $14 \mathrm{~m}^{3}$ ). Um trator de esteira mais potente (D-8) procedeu à escarificação do solo com um equipamento acoplado à tomada de força traseira, denominado ripper, e que apresentava três garras de $100 \mathrm{~cm}$ de comprimento, com distância de $1 \mathrm{~m}$ entre elas. Esse equipamento, uma vez passado no terreno que já se encontrava nivelado, formava as linhas de plantio para as 2.500 mudas ha $^{-1}$, uma vez que o espaçamento preconizado pelo PRAD da empresa era de $2 \mathrm{~m}$ entre linhas e $2 \mathrm{~m}$ na linha de plantio (espaçamento de 2 × $2 \mathrm{~m}$ ).

Nesse processo, a terra-preta superficial caía dentro das linhas (no sulco), o que é interessante e desejável por favorecer, devido à maior disponibilidade de matéria

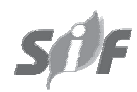

Revista Árvore, Viçosa-MG, v.38, n.1, p.1-24, 2014 
orgânica e água, o estabelecimento e desenvolvimento da futura muda ali plantada. Essa operação foi feita no fim do verão (outubro-dezembro), enquanto o solo ainda estava relativamente seco e para que as primeiras chuvas de janeiro pudessem levar mais "terra preta" para os sulcos (linhas de plantio). No início do período chuvoso (janeiro), foram realizados os plantios florestais (reflorestamentos). A drenagem nas áreas de plantios era excelente, pois a camada de solo estéril chegava até 8-10 m de profundidade.

Nas linhas de plantio, as mudas deveriam ser plantadas a cada $2 \mathrm{~m}$, perfazendo um total de 2.500 mudas por hectare. A adubação foi feita somente no plantio e era constituída de uma mistura homogeneizada por $10 \mathrm{~min}$, em betoneira composta por quatro carros de mão de terra-preta, três carros de mão de esterco de gado curtido, 450 g de NPK 4-14-8, 150 g de termofosfato magnesiano (Yoorin) e $45 \mathrm{~g}$ de FTE BR 12 (micronutrientes $\mathrm{Zn}=9 \%, \mathrm{Mn}=2 \%, \mathrm{~B}=1,8 \%$, Mo $=0,1 \%, \mathrm{Cu}=0,8 \%, \mathrm{Fe}=3 \%)$. Por ocasião do plantio, em cada cova foram colocadas $40 \mathrm{~g}$ dessa mistura de fertilizantes com mais $40 \mathrm{~g}$ de calcário dolomítico (PRNT $=95 \%, \mathrm{CaO}=32 \%$ e $\mathrm{MgO}=14 \%$ ). Essa adubação foi recomendada pela equipe de solos do Instituto de Pesquisas da Amazônia (INPA).

As espécies plantadas encontram-se relacionadas na Tabela 1. As mudas foram produzidas no viveiro florestal da empresa no ano anterior ao plantio, ou seja, em 1995. A empresa empregava 66 pessoas, de janeiro a maio, para a execução do plantio de mudas no campo, distribuídas da seguinte forma (Jenaldo Carvalho/MRN - comunicação pessoal, 2006): (i) 10 pessoas ficavam no viveiro preparando o mix de mudas nas caixas que iriam para o campo - o mix refere-se à mistura de mudas em caixas (geralmente 24 mudas/ caixa) com espécies de madeira branca (pioneiras) e de lei (climácicas). Quando a empresa reflorestava áreas pequenas (20-50 ha), o mix era formado por 50\% de espécies de cada tipo (estágio sucessional); atualmente, como as áreas são grandes (c.a. 300 ha), a proporção é de $70 \%$ de pioneiras e 30\% de climácicas; (ii) duas ficavam na preparação da mistura de fertilizantes empregada no plantio; e (iii) 54 formavam duas turmas de plantio com 27 pessoas em cada turma, que tinham as seguintes tarefas: (i) abertura da cova na linha de plantio ( $\pm 25,0$ cm de profundidade); (ii) colocação de calcário dolomítico e a mistura de fertilizante; (iii) distribuição das mudas ao longo da linha de plantio
- observando sempre para que indivíduos da mesma espécie não ficassem vizinhas nas linhas de plantios e, também, aquelas espécies que tinham espaçamento específico; (iv) corte dos sacos de mudas e recolhimento em sacola de lixo; e (v) plantio da muda. Caso ocorresse estiagem de dois dias sucessivos, o plantio deveria ser suspenso. Os 27 integrantes de cada turma dividiam-se nas funções acima, de acordo com a demanda da área. Não existia trabalhador fixo em cada função. As pessoas da turma eram incentivadas a trocar de função para que a tarefa não ficasse muito repetitiva e enfadonha. Normalmente, uma turma plantava cerca de 250 caixas dia $^{-1}$. Como uma caixa continha 24 mudas, o rendimento era de 6.000 mudas dia $^{-1}$ turma $^{-1}$; no caso de duas turmas, tinha-se um rendimento de 12.000 mudas $\mathrm{dia}^{-1}$. Em outras palavras, aproximadamente 4,8 ha (2.500 mudas ha-1 no espaçamento de $2 \times 2 \mathrm{~m}$ ) eram plantados diariamente pelas duas turmas de plantio.

\section{RESULTADOS}

Para o reflorestamento de 1996, foram avaliados os dados de 89 espécies distribuídas em 23 famílias, com número de indivíduos (n) por espécie variando de 1 a 109, nas 23 parcelas permanentes de 0,025 ha, que totalizaram 0,575 ha (Tabela 1); 17 indivíduos ficaram como espécie indeterminada no ano de implantação do monitoramento do reflorestamento e, assim, permaneceram, pois, no segundo ano do monitoramento (1997), haviam morrido, razão por que, dessa forma, não foi possível identificá-los posteriormente.

Para o cálculo dos incrementos periódicos anuais do DAS e da altura e da taxa de mortalidade, foram analisados os dados de 69 espécies no período de 13 anos e, para o cálculo do incremento periódico anual do DAP, os dados de 57 espécies no período de 11 anos.

\subsection{Densidade de plantio}

Foi estimada uma densidade média de plantio de 3.499 mudas ha $^{-1}$; média de 39,3^49,6 mudas por espécie; 29 espécies (32,6\% do total), entre as 89 empregadas, apresentaram densidades superiores à média. Doze espécies plantadas no reflorestamento de 1996 apresentaram, em 2009, densidade de plantio superior a 100 indivíduos ha-1, com taxas de mortalidade, no período de 13 anos (1996 a 2009), variando de 6,5\% (Tapirira guianensis com 160 mudas ha-1) a 97,8\% (Leucaena leucocephala, com 158 mudas ha-1 $^{-1}$. Entre 












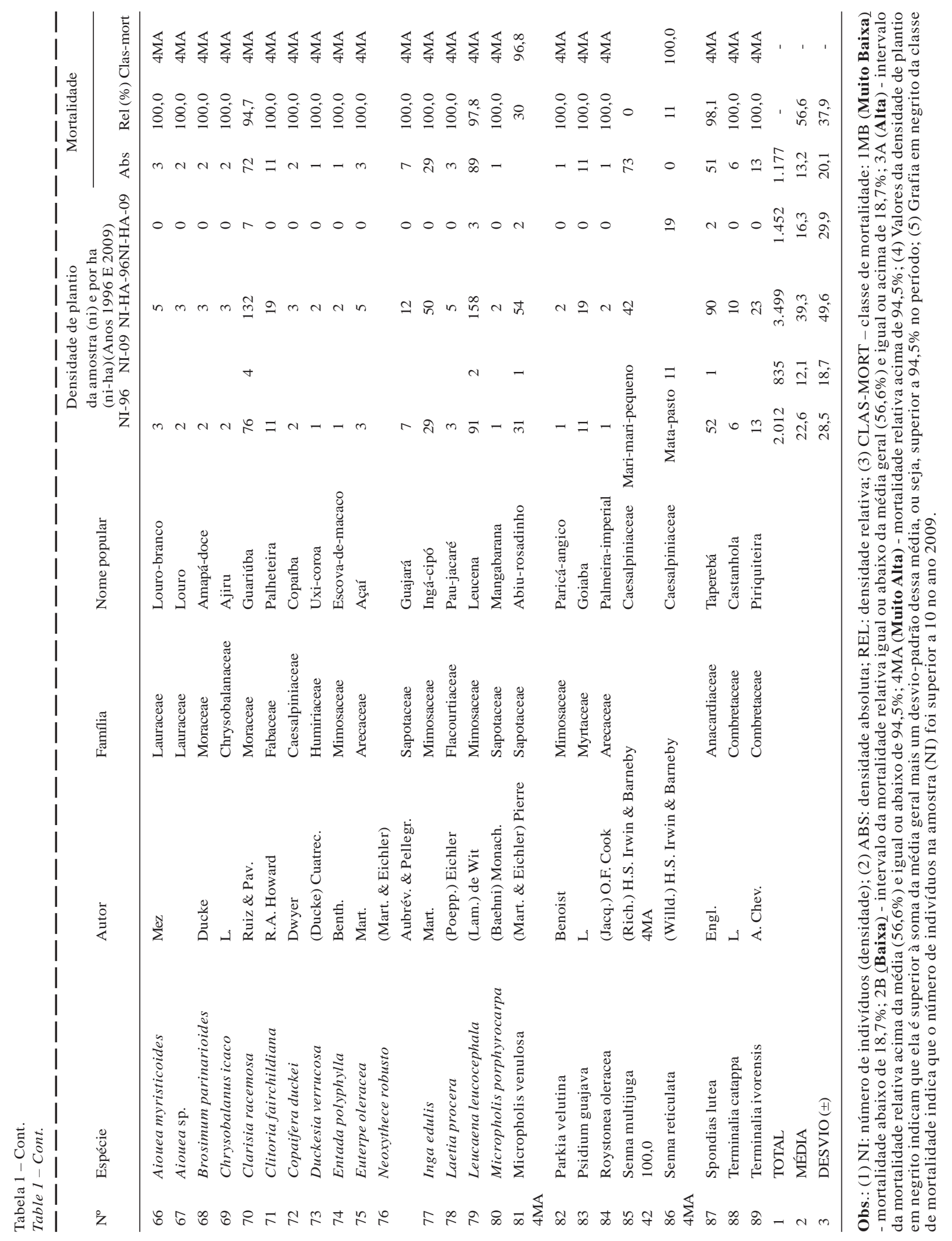


essas mudas de maior densidade, outras cinco demonstraram taxas de mortalidade no período superior a 80\%: Clarisia racemosa (132 mudas ha-1), Genipa americana (165), Pouteria speciosa (129), Abarema turbinata (141) e Acacia polyphylla (143). Doze espécies foram plantadas com a menor densidade (duas mudas ha $^{-1}$ ) naquele ano (Tabela 1 ).

Considerando como densidade excessiva o plantio de mudas de determinada espécie, cuja quantidade tenha sido superior à média geral de todas as espécies (39,3 mudas), somada a um valor do desvio-padrão $(49,6)$, ou seja, superior a 89 mudas ha ${ }^{-1}$, constatou-se que 15 espécies, ou 16,8\% do total, tiveram superdimensionamento do número de mudas plantadas em 1996 (Tabela 1, coluna NI-96, valores em negrito). Em contraposição, outras 60 espécies (67,4\% do total) tiveram o número de mudas ha-1 plantadas inferior à média geral.

\subsection{Mortalidade}

No período analisado, 20 espécies apresentaram mortalidade de $100 \%$, ressaltando-se que, entre essas, seis tinham mais de 10 indivíduos na amostragem: Senna multijuga $(\mathrm{n}=42)$, Inga edulis $(\mathrm{n}=29)$, Terminalia ivorensis - exótica $(\mathrm{n}=13)$, Senna reticulata $(\mathrm{n}=11)$, Clitoria fairchildiana $(\mathrm{n}=11)$ e Psidium guajava introduzida $(\mathrm{n}=11)$. No outro extremo, 15 espécies apresentaram $0 \%$ de mortalidade. No entanto, como o número de indivíduos na amostra foi inferior a 10, essas espécies devem ser consideradas com ressalvas. Foi registrada mortalidade igual ou superior a 50\% para 51 espécies, enquanto outras 21 se encontravam no intervalo entre $10 \%$ e $50 \%$; somente duas espécies (n e” 10) apresentaram mortalidade inferior a 10\%: Tapirira guianensis ( $\mathrm{n}=92$ indivíduos) e Bowdichia nitida $(\mathrm{n}=21)$, com respectivamente $6,5 \%$ e $4,8 \%$ no período de 13 anos (Tabela 1).

A mortalidade periódica, entre 1996 e 2009, dos indivíduos das 89 espécies, em termos relativos, foi de 56,6\% $\pm 37,9 \%$, média de 4,35\% ao ano. Considerando-se como de muito baixa mortalidade, as espécies que apresentaram taxas inferiores ao valor da média geral (56,6\%) menos um desvio-padrão (37,9\%), ou seja, mortalidade inferior a $18,7 \%$, poder-se-ia inferir que 19 espécies foram assim classificadas. Contudo, entre essas, apenas três apresentaram número de indivíduos (n) iguais ou superiores a 10 na amostra: Enterolobium schomburgkii (15,7\%), Tapirira guianensis (6,5\%) e
Bowdichia nitida (4,8\%); as duas últimas poderiam ser consideradas como de excepcional baixa taxa de mortalidade no período de 13 anos de monitoramento. As demais 16 espécies dessa categoria, devido ao reduzido número de indivíduos na amostra $(\mathrm{n}<10)$, deveriam ser consideradas com cautela nos trabalhos de restauração (Tabela 1).

Analogamente, considerando-se como de muito alta mortalidade as espécies que se encontravam acima da média geral acrescida de um desvio-padrão, ou seja, mortalidade igual ou superior a 94,5\%, foram observadas 24 espécies. Uma dezena destas, com n e” 10, deveriam ser descartadas, a priori, nos futuros plantios florestais: Leucaena leucocephala, Clarisia racemosa, Spondias lutea, Senna multijug, Micropholis venulosa, Inga edulis, Terminalia ivorensis, Clitoria fairchildiana, Psidium guajava e Senna reticulata.

As 21 espécies que se encontravam no intervalo entre a média geral das espécies (56,6\%) e o limite inferior da classe de muito alta mortalidade (94,6\%) foram consideradas como de alta mortalidade nas condições vigentes, no ecossistema artificial a ser restaurado com restrição, talvez aquelas oito espécies com $\mathrm{n}<10$ indivíduos na amostra. A fração majoritária (25 espécies) foi considerada como de baixa mortalidade por situar-se no intervalo entre a média $(56,6 \%)$ e o limite superior $(18,7 \%)$ da classe de muito baixa mortalidade (Tabela 2).

Uma síntese da distribuição do número de espécies por classes de mortalidade é apresentada na Figura 1, assim como para o diâmetro basal (DAS) e o diâmetro a 1,30 m do solo (DAP) e, também, para a altura total da árvore (ALT).

\subsection{Incremento do crescimento diamétrico}

\subsubsection{Diâmetro ao nível do solo (DAS)}

O incremento periódico anual médio do crescimento do diâmetro basal das 69 espécies que apresentavam indivíduos registrados no ano 0 (1996) e que se mantiveram vivos até o ano 13 (2009) foi de 0,48 \pm 0,41 $\mathrm{cm} \mathrm{ano}^{-1}$ : 24 espécies, ou pouco mais de $1 / 3$ do total, encontravam-se acima desse limite. No período, apenas uma espécie apresentou incremento superior a $2,0 \mathrm{~cm}$ ano $^{-1}$ Sclerolobium paniculatum $\left(2,5 \mathrm{~cm}^{2} \mathrm{ano}^{-1}\right)$; entre aquele limite e acima de $1,0 \mathrm{~cm}^{2} \mathrm{ano}^{-1}$ foram registradas apenas cinco espécies: Bellucia glossularioides $\left(1,64 \mathrm{~cm} \mathrm{ano}^{-1}\right)$, Tapirira guianensis $\left(1,61 \mathrm{~cm}^{\mathrm{ano}} \mathrm{o}^{-1}\right)$, Simaruba amara $\left(1,24 \mathrm{~cm}^{\mathrm{ano}} \mathrm{o}^{-1}\right)$, Stryphnodendron 
Dinâmica de reflorestamento em áreas de restauração após...

Tabela 2 - Classificação das espécies florestais quanto a mortalidade, incremento periódico anual (IPA) do diâmetro basal (DAS) e da altura total (ALT), porte (relação dos incrementos do diâmetro basal e da altura) e a aptidão ecológica no reflorestamento de 1966, FLONA de Saracá Taquera; Porto Trombetas, Pará.

Table 2 - Forest species classification for mortality, annual periodic increment (IPA) of basal diameter (DAS) and total height (ALT), size (ratio of basal diameter increments and height) and ecological aptitude in reforestation of 1966, National Forest of Saracá Taquera; Porto Trombetas, Pará.

\begin{tabular}{|c|c|c|c|c|c|c|c|c|c|c|}
\hline \multirow{2}{*}{ Espécie } & \multirow{2}{*}{ Ni2009 } & \multicolumn{2}{|c|}{ Mortalidade } & \multicolumn{2}{|c|}{ DAS $\left(\mathrm{CM} \mathrm{ANO}^{-1}\right)$} & \multicolumn{2}{|c|}{ DAP(CM ANO-1) } & \multicolumn{2}{|c|}{ Alt $\left(\mathrm{M} \mathrm{ANO}^{-1}\right)$} & \multirow{2}{*}{$\begin{array}{c}\text { Classe } \\
\text { aptidão }\end{array}$} \\
\hline & & $\operatorname{ReL}(\%)$ & Clas Mort & IPA & Clas Das & IPA & Clas DaP & IPA Alt & Clas Alt & \\
\hline Bowdichia nitida & 20 & 4,8 & $4 \mathrm{MB}$ & 0,94 & $1 \mathrm{MA}$ & 0,70 & $2 \mathrm{~A}$ & 0,96 & $1 \mathrm{MA}$ & Ótima \\
\hline Sclerolobium paniculatum & 9 & 0,0 & $4 \mathrm{MB}$ & 2,50 & $1 \mathrm{MA}$ & 1,45 & 1MA & 1,48 & $1 \mathrm{MA}$ & Ótima \\
\hline Tapirira guianensis & 86 & 6,5 & $4 \mathrm{MB}$ & 1,61 & $1 \mathrm{MA}$ & 1,30 & $1 \mathrm{MA}$ & 1,20 & $1 \mathrm{MA}$ & Ótima \\
\hline Aspidosperma macrocarpon & 3 & 0,0 & $4 \mathrm{MB}$ & 0,69 & $2 \mathrm{~A}$ & 0,60 & $2 \mathrm{~A}$ & 0,72 & $1 \mathrm{MA}$ & Boa \\
\hline Byrsonima crassifolia & 1 & 0,0 & 4MB & 0,56 & $2 \mathrm{~A}$ & 0,38 & 3B & 0,60 & $2 \mathrm{~A}$ & Boa \\
\hline Enterolobium schomburgkii & 70 & 15,7 & $4 \mathrm{MB}$ & 0,37 & 3B & 0,26 & 3B & 0,32 & 3B & Boa \\
\hline Eriotheca globosa & 7 & 0,0 & $4 \mathrm{MB}$ & 0,74 & $2 \mathrm{~A}$ & 0,61 & $2 \mathrm{~A}$ & 0,75 & $1 \mathrm{MA}$ & Boa \\
\hline Licania alba & 1 & 0,0 & 4MB & 0,31 & 3B & 0,31 & 3B & 0,18 & 3B & Boa \\
\hline Licania octandra & 2 & 0,0 & 4MB & 0,42 & 3B & 0,34 & 3B & 0,30 & 3B & Boa \\
\hline Mezilaurus duckei & 1 & 0,0 & 4MB & 0,11 & 3B & & & 0,09 & 3B & Boa \\
\hline Ormosia holerythra & 8 & 0,0 & 4MB & 0,21 & 3B & 0,16 & 3B & 0,19 & 3B & Boa \\
\hline Parkia decussata & 1 & 0,0 & 4MB & 0,59 & $2 \mathrm{~A}$ & 0,46 & $2 \mathrm{~A}$ & 0,52 & $2 \mathrm{~A}$ & Boa \\
\hline Parkia nitida & 8 & 11,1 & 4MB & 0,51 & $2 \mathrm{~A}$ & 0,33 & 3B & 0,45 & $2 \mathrm{~A}$ & Boa \\
\hline Parkia pendula & 3 & 0,0 & 4MB & 0,43 & 3B & 0,17 & 3B & 0,48 & $2 \mathrm{~A}$ & Boa \\
\hline Parkia ulei & 1 & 0,0 & $4 \mathrm{MB}$ & 0,68 & $2 \mathrm{~A}$ & 0,62 & $2 \mathrm{~A}$ & 0,53 & $2 \mathrm{~A}$ & Boa \\
\hline Pouteria eugenifolia & 1 & 0,0 & $4 \mathrm{MB}$ & 0,08 & 3B & & & 0,02 & 4MB & Boa \\
\hline Pseudobombax munguba & 8 & 0,0 & $4 \mathrm{MB}$ & 0,62 & $2 \mathrm{~A}$ & 0,50 & $2 \mathrm{~A}$ & 0,50 & $2 \mathrm{~A}$ & Boa \\
\hline Pterocarpus rhoiri & 4 & 0,0 & 4MB & 0,64 & $2 \mathrm{~A}$ & 0,30 & 3B & 0,40 & $2 \mathrm{~A}$ & Boa \\
\hline Trattinnickia rhoifolia & 1 & 0,0 & $4 \mathrm{MB}$ & 0,75 & $2 \mathrm{~A}$ & 0,40 & $2 \mathrm{~A}$ & 0,77 & 1MA & Boa \\
\hline Astronium gracile & 39 & 31,6 & 3B & 0,31 & 3B & 0,26 & 3B & 0,26 & 3B & Regular \\
\hline Bellucia glossularioides & 1 & 50,0 & 3B & 1,64 & 1MA & 1,41 & 1MA & 0,65 & $2 \mathrm{~A}$ & Regular \\
\hline Caesalpinia ferrea & 35 & 38,6 & 3B & 0,25 & 3B & 0,10 & 3B & 0,16 & 3B & Regular \\
\hline Candoleodendron brachystachyum & 1 & 50,0 & 3B & 0,17 & 3B & & & 0,05 & 4MB & Regular \\
\hline Dalbergia spruceana & 63 & 21,3 & 3B & 0,30 & 3B & 0,15 & 3B & 0,19 & 3B & Regular \\
\hline Geissospermum sericeum & 44 & 45,7 & 3B & 0,31 & 3B & 0,26 & 3B & 0,27 & 3B & Regular \\
\hline Guatteria olivacea & 17 & 34,6 & 3B & 0,47 & 3B & 0,37 & 3B & 0,38 & $2 \mathrm{~A}$ & Regular \\
\hline Guatteria umbonata & 11 & 56,0 & 3B & 0,31 & 3B & 0,26 & 3B & 0,27 & 3B & Regular \\
\hline Hymenaea courbaril & 25 & 35,9 & 3B & 0,37 & 3B & 0,31 & 3B & 0,41 & $2 \mathrm{~A}$ & Regular \\
\hline Hymenaea parvifolia & 4 & 33,3 & 3В & 0,30 & 3B & 0,25 & 3B & 0,35 & 3B & Regular \\
\hline Licania tomentosa & 14 & 39,1 & 3B & 0,39 & 3B & 0,19 & 3B & 0,32 & 3B & Regular \\
\hline Lophanthera lactescens & 24 & 50,0 & 3B & 0,32 & 3B & 0,23 & 3B & 0,32 & 3B & Regular \\
\hline Mezilaurus itauba & 64 & 23,8 & 3B & 0,25 & 3B & 0,21 & 3B & 0,25 & 3B & Regular \\
\hline Micropholis egensis & 10 & 41,2 & 3B & 0,24 & 3B & 0,22 & 3B & 0,09 & 3B & Regular \\
\hline Minquartia guianensis & 2 & 33,3 & 3B & 0,14 & 3B & 0,12 & 3B & 0,18 & 3B & Regular \\
\hline Myrtiluma eugenifolia & 4 & 20,0 & 3B & 0,19 & 3B & 0,17 & 3B & 0,20 & 3B & Regular \\
\hline Oenocarpus bacaba & 3 & 25,0 & 3B & 0,56 & $2 \mathrm{~A}$ & & & 0,20 & 3B & Regular \\
\hline Oеnосагрus bataua var. bataua & 5 & 28,6 & 3B & 0,34 & 3B & & & 0,11 & 3B & Regular \\
\hline Oenocarpus mapora & 6 & 45,5 & 3B & 0,56 & $2 \mathrm{~A}$ & 0,45 & $2 \mathrm{~A}$ & 0,20 & 3B & Regular \\
\hline Parkia multijuga & 65 & 40,4 & 3B & 0,56 & $2 \mathrm{~A}$ & 0,35 & 3B & 0,48 & $2 \mathrm{~A}$ & Regular \\
\hline Stryphnodendron polystachyum & 11 & 26,7 & 3B & 0,37 & 3B & 0,31 & 3B & 0,34 & 3B & Regular \\
\hline Swartzia brachyrachis & 16 & 46,7 & 3B & 0,18 & 3B & 0,35 & 3B & 0,11 & 3B & Regular \\
\hline Swartzia racemosa & 1 & 50,0 & 3B & 0,14 & 3B & & & 0,04 & $4 \mathrm{MB}$ & Regular \\
\hline Tabebuia serratifolia & 24 & 20,0 & 3B & 0,28 & 3B & 0,19 & 3B & 0,27 & 3B & Regular \\
\hline Tachigali alba & 10 & 56,5 & 3B & 0,35 & 3B & 0,38 & 3B & 0,37 & $2 \mathrm{~A}$ & Regular \\
\hline Abarema turbinata & 11 & 86,4 & $2 \mathrm{~A}$ & 0,61 & $2 \mathrm{~A}$ & 0,45 & $2 \mathrm{~A}$ & 0,62 & $2 \mathrm{~A}$ & Baixa \\
\hline Acacia polyphylla & 16 & 80,5 & $2 \mathrm{~A}$ & 0,86 & $2 \mathrm{~A}$ & 0,41 & $2 \mathrm{~A}$ & 0,44 & $2 \mathrm{~A}$ & Baixa \\
\hline Adenanthera pavonina & 1 & 94,1 & $2 \mathrm{~A}$ & 0,41 & 3B & 0,24 & 3B & 0,50 & $2 \mathrm{~A}$ & Baixa \\
\hline
\end{tabular}


Tabela 2 - Cont.

Table 2 - Cont.

\begin{tabular}{|c|c|c|c|c|c|c|c|c|c|c|}
\hline \multirow{2}{*}{ Espécie } & \multirow{2}{*}{ Ni2009 } & \multicolumn{2}{|c|}{ Mortalidade } & \multicolumn{2}{|c|}{ DAS(CM ANO $\left.{ }^{-1}\right)$} & \multicolumn{2}{|c|}{$\mathrm{DAP}\left(\mathrm{CM} \mathrm{ANO}^{-1}\right)$} & \multicolumn{2}{|c|}{$\operatorname{ALT}\left(\mathrm{M} \mathrm{ANO}^{-1}\right)$} & \multirow{2}{*}{$\begin{array}{l}\text { Classe } \\
\text { aptidão }\end{array}$} \\
\hline & & ReL(\%) & Clas Mort & IPA & Clas Das & IPA & Clas DaP & IPa Alt & Clas Alt & \\
\hline Anacardium occidentale & 3 & 90,0 & $2 \mathrm{~A}$ & 1,11 & $1 \mathrm{MA}$ & 0,51 & $2 \mathrm{~A}$ & 0,45 & $2 \mathrm{~A}$ & Baixa \\
\hline Apeiba burchelli & 5 & 66,7 & $2 \mathrm{~A}$ & 0,42 & 3B & 0,39 & 3B & 0,48 & $2 \mathrm{~A}$ & Baixa \\
\hline Apeiba glabra & 5 & 58,3 & $2 \mathrm{~A}$ & 0,42 & 3B & 0,23 & 3B & 0,25 & 3B & Baixa \\
\hline Dinizia excelsa & 1 & 66,7 & $2 \mathrm{~A}$ & 0,30 & 3B & 0,29 & 3B & 0,42 & $2 \mathrm{~A}$ & Baixa \\
\hline Dipteryx magnifica & 1 & 80,0 & $2 \mathrm{~A}$ & 0,18 & $3 B$ & & & 0,06 & 3B & Baixa \\
\hline Dipteryx odorata & 10 & 61,5 & $2 \mathrm{~A}$ & 0,25 & 3B & 0,14 & 3B & 0,28 & 3B & Baixa \\
\hline Dypsis lutescens & 1 & 85,7 & $2 \mathrm{~A}$ & 0,19 & $3 B$ & & & 0,08 & $3 B$ & Baixa \\
\hline Endopleura uchi & 1 & 80,0 & $2 \mathrm{~A}$ & 0,38 & 3B & 0,41 & $2 \mathrm{~A}$ & 0,51 & $2 \mathrm{~A}$ & Baixa \\
\hline Eugenia cumini & 2 & 77,8 & $2 \mathrm{~A}$ & 0,35 & $3 B$ & & & 0,04 & $4 \mathrm{MB}$ & Baixa \\
\hline Genipa americana & 6 & 93,7 & $2 \mathrm{~A}$ & 0,21 & $3 B$ & 0,15 & 3B & 0,13 & 3B & Baixa \\
\hline Guatteria poepigiana & 1 & 87,5 & $2 \mathrm{~A}$ & 0,18 & 3B & 0,07 & $4 \mathrm{MB}$ & 0,12 & 3B & Baixa \\
\hline Platymiscium duckei & 5 & 75,0 & $2 \mathrm{~A}$ & 0,11 & $3 B$ & 0,03 & $4 \mathrm{MB}$ & 0,04 & $4 \mathrm{MB}$ & Baixa \\
\hline Pouteria speciosa & 7 & 90,5 & $2 \mathrm{~A}$ & 0,16 & 3B & 0,20 & 3B & 0,14 & 3B & Baixa \\
\hline Simaruba amara & 11 & 71,8 & $2 \mathrm{~A}$ & 1,24 & $1 \mathrm{MA}$ & 1,00 & $1 \mathrm{MA}$ & 1,07 & $1 \mathrm{MA}$ & Baixa \\
\hline Stryphnodendron guianensis & 2 & 86,7 & $2 \mathrm{~A}$ & 1,23 & $1 \mathrm{MA}$ & 0,99 & 1MA & 1,40 & $1 \mathrm{MA}$ & Baixa \\
\hline Stryphnodendron obovatum & 1 & 75,0 & $2 \mathrm{~A}$ & 0,85 & $2 \mathrm{~A}$ & 0,37 & 3B & 0,52 & $2 \mathrm{~A}$ & Baixa \\
\hline Tabebuia barbata & 2 & 71,4 & $2 \mathrm{~A}$ & 0,25 & 3B & 0,16 & 3B & 0,31 & 3B & Baixa \\
\hline Trattinickia burseraefolia & 1 & 92,9 & $2 \mathrm{~A}$ & 0,52 & $2 \mathrm{~A}$ & 0,80 & $1 \mathrm{MA}$ & 0,68 & $1 \mathrm{MA}$ & Baixa \\
\hline Aiouea myristicoides & 0 & 100,0 & $1 \mathrm{MA}$ & & & & & & & Inapta \\
\hline Aiouea sp. & 0 & 100,0 & $1 \mathrm{MA}$ & & & & & & & Inapta \\
\hline Brosimum parinarioides & 0 & 100,0 & $1 \mathrm{MA}$ & & & & & & & Inapta \\
\hline Chrysobalanus icaco & 0 & 100,0 & $1 \mathrm{MA}$ & & & & & & & Inapta \\
\hline Clarisia racemosa & 4 & 94,7 & 1MA & 0,09 & 3В & & & 0,02 & $4 \mathrm{MB}$ & Inapta \\
\hline Clitoria fairchildiana & 0 & 100,0 & $1 \mathrm{MA}$ & & & & & & & Inapta \\
\hline Copaifera duckei & 0 & 100,0 & $1 \mathrm{MA}$ & & & & & & & Inapta \\
\hline Duckesia verrucosa & 0 & 100,0 & $1 \mathrm{MA}$ & & & & & & & Inapta \\
\hline Entada polyphylla & 0 & 100,0 & $1 \mathrm{MA}$ & & & & & & & Inapta \\
\hline Euterpe oleracea & 0 & 100,0 & $1 \mathrm{MA}$ & & & & & & & Inapta \\
\hline Neoxythece robusto & 0 & 100,0 & $1 \mathrm{MA}$ & & & & & & & Inapta \\
\hline Inga edulis & 0 & 100,0 & $1 \mathrm{MA}$ & & & & & & & Inapta \\
\hline Laetia procera & 0 & 100,0 & $1 \mathrm{MA}$ & & & & & & & Inapta \\
\hline Leucaena leucocephala & 2 & 97,8 & $1 \mathrm{MA}$ & 0,51 & $2 \mathrm{~A}$ & 0,50 & $2 \mathrm{~A}$ & 0,23 & $3 B$ & Inapta \\
\hline Micropholis porphyrocarpa & 0 & 100,0 & 1MA & & & & & & & Inapta \\
\hline Micropholis venulosa & 1 & 96,8 & $1 \mathrm{MA}$ & 0,21 & $3 B$ & & & 0,06 & $3 B$ & Inapta \\
\hline Parkia velutina & 0 & 100,0 & $1 \mathrm{MA}$ & & & & & & & Inapta \\
\hline Psidium guajava & 0 & 100,0 & $1 \mathrm{MA}$ & & & & & & & Inapta \\
\hline Roystonea oleracea & 0 & 100,0 & $1 \mathrm{MA}$ & & & & & & & Inapta \\
\hline Senna multijuga & 0 & 100,0 & $1 \mathrm{MA}$ & & & & & & & Inapta \\
\hline Senna reticulata & 0 & 100,0 & 1MA & & & & & & & Inapta \\
\hline Spondias lutea & 1 & 98,1 & $1 \mathrm{MA}$ & 0,01 & $4 \mathrm{MB}$ & & & 0,01 & $4 \mathrm{MB}$ & Inapta \\
\hline Terminalia catappa & 0 & 100,0 & $1 \mathrm{MA}$ & & & & & & & Inapta \\
\hline Terminalia ivorensis & 0 & 100,0 & $1 \mathrm{MA}$ & & & & & & & Inapta \\
\hline Média & 12,1 & 56,6 & - & 0,48 & - & 0,40 & - & 0,37 & - & - \\
\hline Desvio $( \pm)$ & 18,7 & 37,9 & - & 0,41 & - & 0,31 & - & 0,31 & - & - \\
\hline
\end{tabular}

Obs.: (1) NI: número de indivíduos. (2) Mortalidade (classe de mortalidade): 1MB (Muito Baixa) - mortalidade abaixo de 18,7\%; 2B (Baixa) - intervalo da mortalidade relativa igual ou abaixo da média geral (56,6\%) e igual ou acima de 18,7\%; $3 \mathrm{~A}$ (Alta) - intervalo da mortalidade relativa acima da média (56,6\%) e igual ou abaixo de 94,5\%; 4MA (Muito Alta) - mortalidade relativa acima de 94,5\%. (3) DAS (classes do crescimento do diâmetro basal): 1MA (Muito Alto) - crescimento superior a 0,89 cm ano-1; 2A (Alto) - crescimento igual ou superior a $0,48 \mathrm{~cm}_{\text {ano }}^{-1}$ e inferior ou igual a $0,89 \mathrm{~cm} \mathrm{ano}^{-1}$; $3 \mathrm{~B}$ (Baixo) - crescimento inferior a $0,48 \mathrm{~cm}^{-1}$ ano igual ou superior a $0,07 \mathrm{~cm}^{2} \mathrm{ano}^{-1} ; 4 \mathrm{MB}$ (Muito Baixo) - crescimento inferior a 0,07 $\mathrm{cm}^{\mathrm{ano}}{ }^{-1}$. (4) DAP (classes do crescimento do DAP): $1 \mathrm{MA}$ (Muito Alto) - crescimento superior a $0,71 \mathrm{~cm} \mathrm{ano}^{-1} ; 2 \mathrm{~A}$ (Alto) - crescimento igual ou superior a $0,40 \mathrm{~cm}^{-1} \mathrm{ano}^{-1}$ e inferior ou igual a $0,71 \mathrm{~cm}^{-1} \mathrm{cos}^{-1}$; $3 \mathrm{~B}$ (Baixo) - crescimento igual ou inferior a $0,40 \mathrm{~cm} \mathrm{ano}^{-1}$ e superior ou igual a $0,09 \mathrm{~cm} \mathrm{ano}^{-1}$; $4 \mathrm{MB}$ (Muito Baixo) - crescimento inferior a $0,09 \mathrm{~cm} \mathrm{ano}^{-1}$. (5) ALT (classes do crescimento em altura total): $1 \mathrm{MA}$ (Muito Alto) - crescimento superior a $0,68 \mathrm{~m}$ ano-1; $2 \mathrm{~A}$ (Alto) - crescimento igual ou superior a $0,37 \mathrm{~m}^{2} \mathrm{ano}^{-1}$ e inferior ou igual a $0,68 \mathrm{~m}^{\mathrm{ano}} \mathrm{o}^{-1}$; $3 \mathrm{~B}$ (Baixo) - crescimento inferior a $0,37 \mathrm{~m}^{-1} \mathrm{e}^{-1} \mathrm{e}$ superior ou superior a $0,06 \mathrm{~m}^{-1} \mathrm{ano}^{-1}$; $4 \mathrm{MB}$ (Muito Baixo) - crescimento inferior a 0,06 m ano-1. ApTIDÃo - grafia em negrito da classe de mortalidade indica que o número de indivíduos na amostra (NI) foi superior a 10 no ano 2009 ; ver Tabela 3.

Revista Árvore, Viçosa-MG, v.38, n.1, p.1-24, 2014 


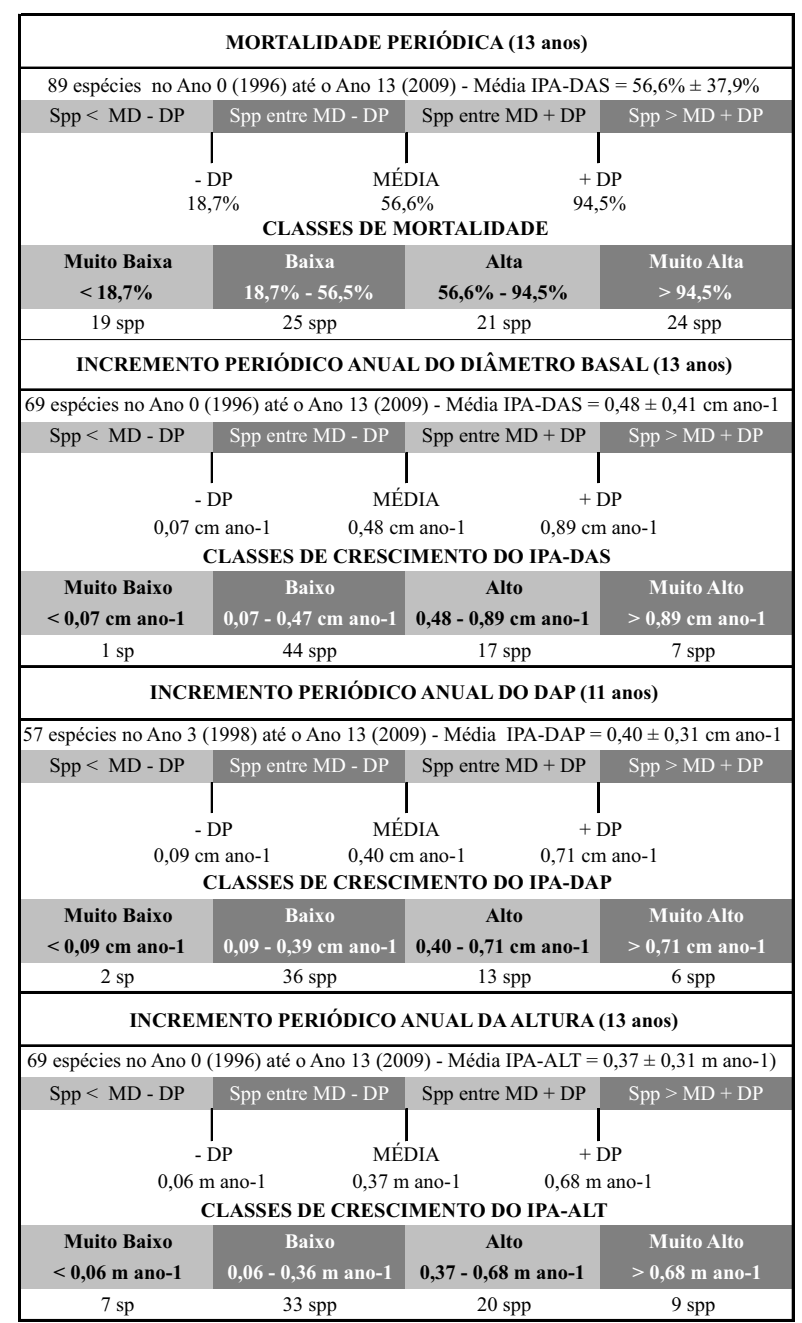

Figura 1 - Número de espécies por classes de mortalidade e dos incrementos periódicos anuais dos diâmetros (DAS e DAP) e da altura total dos indivíduos do reflorestamento de 1996; FLONAde Saracá Taquera, Porto Trombetas (PA).

Figure 1-Number of species per class of mortality and periodic annual diameter increments (DAS and $\mathrm{DBH}$ ) and total height of the individuals in reforesting areas of 1996; FLONA Saracá Taquera, Porto Trombetas (PA).

guianensis (1,23 cm ano-1) e Anacardium occidentale $\left(1,11 \mathrm{~cm}\right.$ ano $\left.^{-1}\right)$. No entanto, apenas Tapirira guianensis apresentou taxa de mortalidade inferior a 50\%; nas demais, a taxa variou de $50 \%$ a $90 \%$. Clarisia racemosa $(\mathrm{n}=76)$, Pouteria eugenifolia $(\mathrm{n}=1)$ e Spondias lutea $(n=52)$ mostraram os menores incrementos - inferiores a $0,10 \mathrm{~cm}$ ano $^{-1}$ (Tabela 2) e altíssimas taxas de mortalidade, superiores a 94\%, à exceção de P. eugenifolia (Tabela 1).
Uma das premissas da restauração florestal baseia-se na preferência por aquelas espécies de maior produção de biomassa (produção primária líquida), no menor espaço de tempo. Nesse sentido, considerando-se que a seleção deva recair sobre aquelas espécies de maior crescimento em diâmetro (1MA) e que estas, neste estudo, seriam aquelas que apresentaram incrementos superiores à média geral $\left(0,48 \mathrm{~cm} \mathrm{ano}^{-1}\right)$ mais um valor do desviopadrão $\left(0,41 \mathrm{~cm}^{2} \mathrm{ano}^{-1}\right)$, ou seja, incrementos superiores a $0,89 \mathrm{~cm} \mathrm{ano}^{-1}$, poder-se-ia, então, inferir que sete espécies seriam, a princípio, as da classe de muito alto crescimento diamétrico (Tabela 2, coluna ClAs DAs: 1MA). Contudo, entre estas, Bellucia glossularioides e Sclerolobium paniculatum são consideradas com ressalvas por terem apresentado, respectivamente, nove e dois indivíduos para geração das estimativas; Simaruba amara, Stryphnodendron guianensis e Anacardium occidentale apresentaram taxas de mortalidade elevadas de, respectivamente, 71,8\%, 86,7\% e 90,0\% no período de 13 anos. Restariam, então, apenas Tapirira guianensis $\left(1,61 \mathrm{~cm} \mathrm{ano}^{-1}\right)$ e Bowdichia nitida $\left(0,94 \mathrm{~cm}^{2} \mathrm{no}^{-1}\right) \mathrm{com}$ ótimo crescimento do diâmetro basal e baixíssimas taxas de mortalidade: 6,5\% e 4,8\%, respectivamente.

Analogamente, considerando como de crescimento muito baixo (4MB) aquelas espécies cujos incrementos em diâmetro sejam inferiores ao valor da média geral $\left(0,48 \mathrm{~cm}^{a n o}{ }^{-1}\right)$, subtraído de um desvio-padrão $\left(0,41 \mathrm{~cm} \mathrm{ano}^{-1}\right)$, ou seja, inferiores a $0,07 \mathrm{~cm}^{\mathrm{ano}}{ }^{-1}$ (Tabela 2, coluna Clas DAs: $4 \mathrm{MB}$ ), foi identificada apenas uma espécie (Spondias lutea), que apresentou um único indivíduo vivo em 2009, entre 52 registrados em 1996, ou seja, mortalidade de98,2\% e incremento periódico anual individual do DAS de apenas 0,01 $\mathrm{cm} \mathrm{ano}^{-1}$.

As espécies da classe de alto crescimento do DAS (2A) foram consideradas como aquelas que se encontravam no intervalo entre a média dos incrementos de todas as espécies ( $\left(\mathrm{e}^{\text {” }} 0,48 \mathrm{~cm}\right.$ ano-1) e o limite inferior das de muito alto crescimento ( $d$ ” $0,89 \mathrm{~cm}^{-1}$ ): 17 espécies se enquadraram nessa classe (Tabela 2, coluna CLAs DAs: 2A). Entretanto, 11 tiveram $\mathrm{n}<10$ indivíduos na amostra; outras quatro espécies (Acacia polyphylla, Abarema turbinata, Trattinickia burseraefolia e Leucaena leucocephala) apresentaram taxas de mortalidade superiores a $80 \%$ no período; Tabebuia serratifolia (20\%) e Enterolobium schomburgkii (15,7\%) exibiram baixas taxas de mortalidade e crescimento regular do DAS.

Revista Árvore, Viçosa-MG, v.38, n.1, p.1-24, 2014 
Analogamente às espécies de alto crescimento, as da classe de baixo crescimento (3B) do diâmetro seriam aquelas situadas no intervalo abaixo da média geral $\left(<0,48 \mathrm{~cm} \mathrm{ano}^{-1}\right)$ e no limite superior da classe de muito baixo crescimento (d" $0,07 \mathrm{~cm} \mathrm{ano}^{-1}$ ), em que se tem a fração majoritária formada por 44 espécies (Tabela 2, coluna ClAs DAs: 3B). Entre essas, 27 ocorreram com $\mathrm{n}<10$ indivíduos; outras cinco (Micropholis venulosa, Clarisia racemosa, Adenanthera pavonina, Genipa americana e Pouteria speciosa) tiveram mortalidade superior a 90\%, enquanto outras 25 tiveram taxas de mortalidade entre 75\% e 21\%; apenas Myrtiluma eugenifolia e Tabebuia serratifolia (20\% cada) e Enterolobium schomburgkii (15,7\%) apresentaram baixas taxas de mortalidade e de crescimento do DAS. Uma síntese da distribuição do número de espécies por classe de incremento do crescimento do diâmetro basal (DAS) é apresentada na Figura 1.

\subsubsection{Diâmetro a 1,30m do solo (DAP)}

O incremento periódico anual médio do DAP de todas as 57 espécies monitoradas no período de 11 abaixo da média. Incrementos muito baixos, iguais ou inferiores a $0,1 \mathrm{~cm} \mathrm{ano}^{-1}$, foram observados em Caesalpinia ferrea $\left(0,10 \mathrm{~cm}^{-1} \mathrm{ano}^{-1}\right)$, Guatteria poepigiana $\left(0,07 \mathrm{~cm} \mathrm{ano}^{-1}\right)$ e Platymiscium duckei $\left(0,03 \mathrm{~cm}^{\mathrm{ano}}{ }^{-1}\right)$. Incrementos próximos a $1,0 \mathrm{~cm}^{2} \mathrm{ano}^{-1}$ foram calculados para Sclerolobium paniculatum, Bellucia glossularioides, Tapirira guianensis, Simaruba amara e Stryphnodendron guianensis, com 1,45; 1,41; 1,30; 1,0; e 0,99 cm ano-1, respectivamente. No entanto, as duas últimas apresentaram taxas de mortalidade muito elevadas de, respectivamente, $71,8 \%$ e $86,7 \%$, contrariamente às de Sclerolobium paniculatum (0\%) e Tapirira guianensis (6,5\%), que foram muito baixas. Bellucia glossularioides, apesar de ter apresentado mortalidade nula, não deve ser considerada devido ao fato de sua estimativa ter-se originado de apenas um indivíduo.

Considerando-se como de muito alto crescimento em DAP aquelas espécies que apresentaram incrementos superiores à média geral $\left(0,40 \mathrm{~cm}_{\text {ano }}{ }^{-1}\right)$ mais um desviopadrão $\left(0,31 \mathrm{~cm} \mathrm{ano}^{-1}\right)$, ou seja, superior a $0,71 \mathrm{~cm}^{2} \mathrm{ano}^{-1}$, seriam indicadas, a priori, seis espécies (Tabela 2, coluna ClAs DAP: 1MA). Contudo, entre essas, Bellucia glossularioides e Sclerolobium paniculatum apresentaram n < 10; Simaruba amara, Stryphnodendron guianensis e Trattinickia burseraefolia deveriam ser vistas com ressalvas por terem apresentado taxas de mortalidade superiores a $71 \%$ no período de 11 anos. Sobrariam, então, Tapirira guianensis $\left(1,30 \mathrm{~cm} \mathrm{ano}^{-1}\right)$ e Sclerolobium paniculatum $\left(1,45 \mathrm{~cm} \mathrm{ano}^{-1}\right)$, ambas com baixíssima taxa de mortalidade.

As 13 espécies cujos incrementos foram inferiores a $0,71 \mathrm{~cm} \mathrm{ano}^{-1}$ e igual ou acima da média $\left(0,40 \mathrm{~cm} \mathrm{ano}^{-1}\right)$ foram consideradas como de alto crescimento (Tabela 2, coluna ClAs DAP: 2A). Todavia, entre essas, foram registradas sete espécies com $\mathrm{n}<10$ indivíduos na amostra; outras quatro (Acacia polyphylla, Abarema turbinata, Anacardium occidentale, Endopleura uchi e Leucaena leucocephala) deveriam ser descartadas para o plantio nessas condições, por terem apresentado taxa de mortalidade igual ou superior a $80 \%$. Restariam, então, Oenocarpus mapora e Bowdichia nítida, esta com mortalidade muito baixa e aquela com alto aumento em DAP e baixa mortalidade.

As espécies de baixo crescimento consideradas como aquelas cujo incremento se encontrava abaixo da média $\left(0,39 \mathrm{~cm}\right.$ ano $\left.^{-1}\right)$ e igual ou acima do limite inferior das espécies de crescimento muito baixo $\left(0,09 \mathrm{~cm} \mathrm{ano}^{-1}\right)$ constituíram o grupo majoritário, formado por 36 espécies (Tabela 2, coluna ClAs DAP: 3B). Considerando-se como de crescimento muito baixo aquela espécie cujo incremento foi inferior ao valor da média geral subtraído de um desvio-padrão, ou seja, inferior a $0,09 \mathrm{~cm}^{2} \mathrm{ano}^{-1}$, foram identificadas duas espécies: Guatteria poepigiana e Platymiscium duckei, ambas com taxas de mortalidade superiores a 75\% (Tabela 2, coluna ClAs DAP: 4MB). Uma síntese da distribuição do número de espécies por classe de incremento do crescimento do diâmetro a 1,30 m do solo (DAP) é apresentada na Figura 1.

\subsection{Incremento do crescimento em altura}

O incremento periódico anual médio do crescimento em altura total para as 69 espécies analisadas foi estimado em $0,37 \pm 0,31 \mathrm{~m} \mathrm{ano}^{-1}$; igual ou superior à média, foram observadas 29 espécies (Tabela 2). Quatro espécies apresentaram aumentos iguais ou superiores a 1,0 m ano-1: Sclerolobium paniculatum, Stryphnodendron guianensis, Tapirira guianensis e Simaruba amara, com 1,48; 1,40; 1,20; e 1,07 m ano${ }^{1}$, respectivamente. No entanto, a segunda e a última apresentaram taxas de mortalidade superiores a $70 \%$ no período considerado. Doze espécies exibiram incrementos inferiores a $0,10 \mathrm{~m} \mathrm{ano}^{-1}$, sendo em sete delas o número de indivíduos na amostra inferior a 10; três apresentaram altas taxas de mortalidade, acima 
de 95\% (Clarisia racemosa, Spondias lutea e Micropholis venulosa) e outra (Platymiscium duckei) de $75 \%$, no período analisado.

Considerando que nas áreas a restaurar se deve dar preferência àquelas espécies de maior crescimento em altura e que apresentaram incrementos superiores à média geral $\left(0,37 \mathrm{~m}_{\text {ano }}{ }^{-1}\right)$ mais um desvio-padrão $\left(0,31 \mathrm{~m} \mathrm{ano}^{-1}\right)$, ou seja, incremento periódico anual da altura superior a $0,68 \mathrm{~m}^{2} \mathrm{ano}^{-1}$ seria de muito alto crescimento em altura, podendo-se, então, inferir que nove espécies seriam, a princípio, selecionadas (Tabela 2, coluna Clas Alt: 1MA). Contudo, entre essas, Sclerolobium paniculatum (1,48 $\left.\mathrm{m}^{-1} \mathrm{ano}^{-1}\right)$, Trattinnickia rhoifolia $\left(0,77 \mathrm{~m}^{2} \mathrm{ano}^{-1}\right)$, Eriotheca globosa $(0,75 \mathrm{~m}$ ano $\left.^{-1}\right)$ e Aspidosperma macrocarpon (0,72 $\left.\mathrm{m} \mathrm{ano}^{-1}\right)$ deveriam ser consideradas com ressalva por terem apresentado $\mathrm{n}<10$ indivíduos na amostra para geração das estimativas. Entretanto, levando-se em conta também a mortalidade nula dessas durante todo o período do monitoramento, elas deveriam ser consideradas como de ótimo potencial de crescimento em altura. Stryphnodendron guianensis, Simaruba amara e Trattinickia burseraefolia deveriam ser preteridas por terem apresentado altas taxas de mortalidade, superiores a $70 \%$, no período de 13 anos. Tapirira guianensis $\left(1,2 \mathrm{~m}^{a n o} \mathrm{~s}^{-1}\right)$ e Bowdichia nitida $\left(0,96 \mathrm{~m} \mathrm{ano}^{-1}\right)$, ambas com baixíssima taxa de mortalidade, foram consideradas como de alto crescimento em altura.

Considerando-se como as de muito baixo crescimento aquelas espécies cujos incrementos apresentaram valores inferiores ao da média geral $\left(0,37 \mathrm{~m} \mathrm{ano}^{-1}\right)$ subtraídos de um desvio-padrão $\left(0,31 \mathrm{~m}^{\mathrm{ano}}{ }^{-1}\right)$, ou seja, inferiores a $0,06 \mathrm{~m} \mathrm{ano}^{-1}$, foram registradas sete espécies (Tabela 2, coluna ClAs Alt: 4MB). Entre elas, quatro ocorreram com menos de 10 indivíduos na amostra e mortalidade zero no período considerado. Clarisia racemosa, Spondias lutea, Micropholis venulosa e Platymiscium duckei, concomitantemente ao baixíssimo incremento em altura, apresentaram altíssimas taxas de mortalidade, superiores a $94 \%$ as duas primeiras e, respectivamente, $75 \%$ e $77,8 \%$ as duas últimas.

Abaixo de 0,68 $\mathrm{m}^{2} \mathrm{ano}^{-1}$ e igual ou acima da média $\left(0,37 \mathrm{~m} \mathrm{ano}^{-1}\right)$, foram registradas 20 espécies, que poderiam ser consideradas como de alto crescimento em altura nas condições vigentes nas áreas a restaurar (Tabela 2, coluna Clas Alt: 2A). Entretanto, 11 delas, com $n<$ 10 indivíduos na amostra, deveriam ser consideradas com cautela. Adenanthera pavonina, Anacardium occidentale, Abarema turbinata, Acacia polyphylla e Endopleura uchi, com taxas de mortalidade iguais ou superiores a $80 \%$, deveriam ser vistas com ressalvas nos futuros reflorestamentos da empresa; no entanto, as outras seis, com taxas de mortalidade zero, deveriam ser plantadas em maior número (Pseudobombax munguba, Pterocarpus rhoiri, Parkia pendula, Byrsonima crassifolia, Parkia ulei e Parkia decussata). Quatro espécies: Tachigali alba, Parkia multijuga, Hymenaea courbaril e Guatteria olivacea, com taxas de mortalidade inferiores a 40\%, à exceção da primeira, com $57 \%$ no período, foram consideradas espécies de bom crescimento em altura nas áreas anuais de restauração florestal.

As espécies no intervalo abaixo da média $(0,36 \mathrm{~m}$ $\mathrm{ano}^{-1}$ ) e igual ou acima do limite superior das de baixíssimo incremento em altura $\left(0,06 \mathrm{~m} \mathrm{ano}^{-1}\right)$, consideradas como de baixo crescimento, totalizaram 33 espécies (Tabela 2, coluna ClAs Alt: 3B). Entre essas, 13 ocorreram com $\mathrm{n}<10$ indivíduos na amostra. Outras três (Leucaena leucocephala, Genipa americana, Micropholis venulosa e Pouteria speciosa) tiveram mortalidade superior a 90\%. Uma síntese da distribuição do número de espécies por classe de incremento do crescimento da altura total é apresentada na Figura 1.

\subsection{Aptidão ecológica das espécies}

A aptidão para restauração de uma espécie foi analisada pelo comportamento do incremento periódico anual do diâmetro e da altura, concomitantemente à taxa de mortalidade. Obviamente, outras questões também se encontram relacionadas, como: a competição dessas árvores oriundas do reflorestamento com aquelas provenientes da regeneração natural (SALOMÃO et al., 2007), o estágio sucessional da espécie, as características físicas do solo (retenção de água, porosidade etc.), a fertilidade, a acidez, o teor de matéria orgânica (relação C/N) e as micro e mesofaunas do solo, entre outras.

As 89 espécies monitoradas desde 1996 (ano 0) foram agrupadas em cinco classes de aptidão em relação ao seu desenvolvimento no ecossistema artificial formado pela restauração florestal de áreas de pós-lavra na Amazônia (Tabela 3): ótima (3 espécies, ou 3,4\% do total), boa (16 ou 18,0\%), regular ( 25 ou $28,1 \%$ ), baixa (21 ou 23,6\%) e inapta (24 ou 27,0\%). Consideraram-se, a priori, as espécies na classe de mortalidade muito

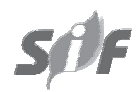

Revista Árvore, Viçosa-MG, v.38, n.1, p.1-24, 2014 
alta, superior a 94,5\% no período de 13 anos como inaptas, independentemente da classificação dos incrementos periódicos anuais do diâmetro e da altura. Analogamente, espécies com mortalidade muito baixa, inferior a 18,7\%, foram consideradas aptas e classificadas de acordo com os graus de aptidão adotados em função dos incrementos do diâmetro basal e da altura.

Apenas Tapirira guianensis, Bowdichia nitida e Sclerolobium paniculatum foram consideradas como de ótima aptidão por apresentarem mortalidade muito baixa e muito alto IPA do diâmetro e da altura. Todavia, há de se ressaltar que a última ocorreu com nove indivíduos na amostra (Tabela 2).

Dezesseis espécies foram classificadas como de boa adaptabilidade por terem apresentado: (i) mortalidade muito baixa; (ii) incremento periódico anual do diâmetro alto ou baixo e o da altura em qualquer das classes adotadas. Entre essas, apenas Enterolobium schomburgkii ocorreu com mais de 10 indivíduos na amostra $(\mathrm{n}=83)$.

A fração majoritária das espécies (25) foi classificada como de aptidão ecológica regular por apresentar: (i) mortalidade baixa; (ii) incremento periódico anual do diâmetro muito alto, alto ou baixo; e (iii) incremento da altura alto, baixo ou muito baixo. Oito espécies dessa classe ocorreram com menos de 10 indivíduos na amostra.

Com baixa aptidão ecológica foram classificadas 21 espécies, que foram caracterizadas como aquelas com mortalidade alta e incremento periódico anual do diâmetro muito alto, alto ou baixo e o da altura em qualquer das classes adotadas. Oito espécies dessa classe ocorreram com menos de 10 indivíduos na amostra.

Das 24 espécies caracterizadas como inaptas, quatro apresentaram mortalidade muito alta (acima de 94,5\% e abaixo de 98,2\%) e incrementos do diâmetro alto, baixo ou muito baixo e da altura baixo ou muito baixo. As demais 20 espécies são aquelas que apresentaram $100 \%$ de mortalidade no período de 13 anos e não foram analisadas quanto aos incrementos periódicos anuais do diâmetro e da altura, pelo fato de todos os seus indivíduos terem morrido antes de 2009.

\section{DISCUSSÃO}

\subsection{Densidade de Plantio}

A densidade média de plantio estimada através dos dados das 23 unidades amostrais do reflorestamento

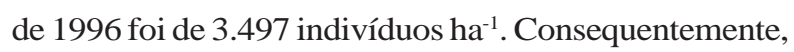
o espaçamento previamente planejado de $2 \times 2 \mathrm{~m}\left(4 \mathrm{~m}^{2}\right.$

Tabela 3 - Síntese dos critérios de classificação da aptidão ecológica das espécies do reflorestamento de 1996; FLONA de Saracá Taquera, Porto Trombetas (PA).

Table 3 - Summary of criteria for classifying the ecological suitability of species in the reforestation of 1996; FLONA of Saracá Taquera, Porto Trombetas (PA).

\begin{tabular}{ll} 
Classes de aptidão ecológica das espécies & Descritores: classes de mortalidade e de incrementos do diâmetro e da altura \\
\hline ÓTIMA: 3 espécies $(3,4 \%)$ & Mortalidade Muito Baixa \\
& IPA-DAS e IPA-ALT Muito Alto \\
BOA: 16 espécies $(18,0 \%)$ & Mortalidade Muito Baixa \\
& IPA-DAS: Alto ou Baixo/IPA-ALT: qualquer \\
REGULAR: 25 espécies (28,1\%) & Mortalidade Baixa \\
& IPA-DAS: Muito Alto, Alto ou Baixo/IPA-ALT: Alto, Baixo ou Muito Baixo \\
BAIXA: 21 espécies $(23,6 \%)$ & Mortalidade Alta \\
& IPA-DAS: Muito Alto, Alto ou Baixo/IPA-ALT: qualquer \\
INAPTA: 24 espécies $(27,0 \%)$ & Mortalidade Muito Alta \\
& IPA-DAS: Alto, Baixo ou Muito Baixo/IPA-ALT: Baixo ou Muito Baixo
\end{tabular}

Obs.: MoRTAlidade (classe de mortalidade): Muito Baixa - mortalidade abaixo de 18,7\%; Baixa - intervalo da mortalidade relativa igual ou abaixo da média geral (56,6\%) e igual ou acima de 18,7\%; Alta - intervalo da mortalidade relativa acima da média (56,6\%) e igual ou abaixo de 94,5\%; Muito Alta - mortalidade relativa acima de 94,5\%. (3) IPA-DAS (classes de incremento periódico anual do diâmetro basal): Muito Alto - crescimento superior a $0,89 \mathrm{~cm} \mathrm{ano}^{-1}$; Alto - crescimento igual ou superior a $0,48 \mathrm{~cm}^{-1}$ ano e inferior ou igual a 0,89 $\mathrm{cm} \mathrm{ano}^{-1}$; Baixo - crescimento inferior a $0,48 \mathrm{~cm}^{\mathrm{ano}}{ }^{-1} \mathrm{e}$ igual ou superior a $0,07 \mathrm{~cm}^{-1} \mathrm{cos}^{-1}$; Muito Baixo - crescimento inferior a 0,07 $\mathrm{cm} \mathrm{ano}^{-1}$. (4) IPA-DAP (classes de incremento periódico anual do DAP): Muito Alto - crescimento superior a 0,71 $\mathrm{cm}^{-1} \mathrm{ano}^{-1}$; Alto - crescimento igual ou superior a $0,40 \mathrm{~cm}_{\text {ano }}^{-1} \mathrm{e}$ inferior ou igual a $0,71 \mathrm{~cm} \mathrm{ano}^{-1}$; Baixo - crescimento igual ou inferior a $0,40 \mathrm{~cm}^{-1}$ ano superior ou igual a 0,09 $\mathrm{cm} \mathrm{ano}^{-1}$; Muito Baixo - crescimento inferior a 0,09 $\mathrm{cm} \mathrm{ano}^{-1}$. (5) IPA-ALT (classes de incremento periódico anual da altura total): Muito Alto - crescimento superior a $0,68 \mathrm{~m}^{-1 n o^{-1}}$; Alto - crescimento igual ou superior a $0,37 \mathrm{~m}$ ano-1 e inferior ou igual a $0,68 \mathrm{~m} \mathrm{ano}^{-1}$; Baixo - crescimento inferior a $0,37 \mathrm{~m} \mathrm{ano}^{-1}$ e superior ou superior a 0,06 m ano-1; e Muito Baixo - crescimento inferior a $0,06 \mathrm{~m}$ ano $^{-1}$.

Revista Árvore, Viçosa-MG, v.38, n.1, p.1-24, 2014 
por muda) não foi observado em campo e, sim, outro inferior, uma vez que a área calculada por muda foi de $2,86 \mathrm{~m}^{2}$.

De acordo com o Programa de Recuperação de Áreas Degradadas (PRAD) da empresa mineradora, deveriam ser plantadas 2.500 mudas ha-1. Todavia, neste estudo ficou constatado que a estimativa da densidade de plantio, no ano 1996, foi de aproximadamente 3.500 mudas ha $^{-1}$. Considerando, então, a densidade como prevista originalmente no PRAD, o número médio de mudas por hectare, para as 89 espécies empregadas, deveria ser de aproximadamente 28 mudas por espécie. Acima desse limite foram registradas 33 espécies; consequentemente, as demais, equivalentes a praticamente $2 /{ }_{3}$ do total, ficaram abaixo da densidade ideal. Observando os extremos, constatou-se que 10 espécies foram plantadas com mais de 100 mudas ha ${ }^{-1}$, enquanto de outras 35 espécies foram plantadas menos de 10 mudas ha-1 $^{-1}$ (Tabela 1 ). Uma distribuição mais equitativa do número de mudas por espécie é importante de ser observada nas futuras áreas anuais de restauração florestal da FLONA.

Os plantios de alta densidade e a indução da regeneração natural têm sido as práticas mais recomendadas para recuperação de fragmentos degradados, podendo ainda, segundo Rodrigues e Gandolfi (2000), ser utilizadas em áreas muito degradadas e que não conservam nenhuma das características bióticas da formação original. A restauração ecológica envolve o atendimento a pelo menos nove atributos listados em SER (2004). Salomão et al. (2012) desenvolveram um modelo para determinação das espécies-chave de uma comunidade florestal e do respectivo número de mudas a plantar por ha em áreas de restauração florestal, com base em análise multivariada envolvendo seis variáveis quantitativas (abundância, frequência, dominância, biomassa, valor comercial da madeira e quantidade de produtos florestais não madeireiros - PFNM) e igual número de variáveis qualitativas dessas mesmas variáveis. O modelo foi aplicado a 898 espécies que foram relacionadas no inventário florestal do Platô Saracá, na FLONA de Saracá Taquera, resultando na seleção de 25 espécies-chave, que tiveram também estimadas as respectivas densidades de plantio em áreas mineradas na Amazônia, com condições biológicas e ambientais semelhantes às relatadas neste estudo.
Em 1996, a densidade de plantio no reflorestamento foi de 3.500 mudas ha ${ }^{-1}\left(2,86 \mathrm{~m}^{2}\right.$ planta $\left.^{-1}\right)$. No ano 2009, a densidade média estimada foi de 1.452 árvores ha ${ }^{-1}\left(6,89 \mathrm{~m}^{2}\right.$ planta $\left.^{-1}\right)$, ou seja, houve drástica queda de $58,5 \%$ na densidade de plantio no período de 13 anos (4,5\% ao ano). Caso houvesse a manutenção do espaçamento previsto no PRAD, de 2.500 mudas ha-1 $\left(4,0 \mathrm{~m}^{2}\right.$ planta $\left.^{-1}\right)$ em 1996, após 13 anos era esperado algo em torno de 1.038 árvores ha-1 $\left(9,63 \mathrm{~m}^{2}\right.$ planta $\left.^{-1}\right)$.

Em um fragmento de floresta ombrófila densa, em Peixe-Boi, PA, Salomão et al. (2002) estimaram, baseados na média de três parcelas permanentes de 1 ha cada, 462 indivíduos ha-1 (DAP $10 \mathrm{~cm}$ ), 2.857 indivíduos ha-1 ( $2 \mathrm{~cm} £$ DAP $£ 5 \mathrm{~cm}$ ) e 116.000 indivíduos ha-1 (DAP $<2 \mathrm{~cm}$ ), ou seja, média de 120.182 indivíduos em 1 ha de floresta. Concluíram informando que o estoque médio de mudas para obter uma árvore era de 297.

Considerando que atualmente a empresa adota o espaçamento de 3 x 2 m plantando 1.667 mudas ha $^{-1}$ (6,0 $\mathrm{m}^{2}$ planta $^{-1}$ ) e a se manter a tendência observada no reflorestamento de 1996, pode-se projetar que um reflorestamento realizado nessas circunstâncias deverá ter 13 anos após, algo próximo de 692 árvores ha" ${ }^{-1}\left(14,45 \mathrm{~m}^{2}\right.$ planta $\left.^{-1}\right)$. Outra questão deverá ser investigada pelo monitoramento: quantos anos seriam necessários para que houvesse estabilização do número de árvores por unidade de área ou, em outras palavras, qual seria a área ideal por muda plantada nesses ecossistemas artificiais restaurados após a atividade minerária?

Existem vários métodos na literatura que orientam os princípios ecológicos que devem ser observados na densidade inicial de plantio. A restauração ecológica envolve o atendimento a minimamente nove atributos listados pela SER (2004). Entre esses, destaca-se que o ecossistema restaurado deve conter um conjunto característico de espécies-chave que ocorrem no ecossistema de referência, fornecendo estrutura apropriada de comunidade e, também, que seja constituído do maior número possível de espécies nativas. Vieira et al. (2009) citaram, entre outros métodos de restauração ativa, o Plantio Adensado de Árvores, em que se planta grande número de árvores (>1.000 ha-1), majoritariamente de espécies pioneiras, criando, assim, rapidamente um ambiente adequado para as espécies das fases tardias da sucessão que, consequentemente, propiciarão aumento da diversidade (REAY; NORTON, 1999). As espécies escolhidas devem ser tolerantes

Revista Árvore, Viçosa-MG, v.38, n.1, p.1-24, 2014 
ao ambiente do local de plantio, potencialmente atrativas a dispersores, e reproduzir rapidamente (LAMB; GILMOUR, 2003).

\subsection{Mortalidade}

Neste trabalho, num período de 13 anos, 20 espécies apresentaram $100 \%$ de mortalidade, enquanto outras 15 espécies tiveram $0 \%$ de mortalidade. A mortalidade periódica, entre 1996 e 2009, dos indivíduos das 89 espécies, em termos relativos, foi de 56,6 \pm 37,9, média de $4,35 \%$ ao ano. Tapirira guianensis e Bowdichia nitida foram consideradas como de excepcional baixa taxa de mortalidade: respectivamente, 6,5\% e 4,8\% no período, juntamente com aquelas 15 espécies com mortalidade nula. Com alto grau de mortalidade foram observadas 10 espécies que deveriam ser descartadas, a priori, nos futuros plantios florestais na FLONA: Senna multijuga, Inga edulis, Terminalia ivorensis, Senna reticulata, Clitoria fairchildiana, Psidium guajava, Spondias lutea, Leucaena leucocephala, Micropholis venulosa e Clarisia racemosa. Vinte e três espécies foram classificadas na classe de mortalidade medianamente alta para as condições vigentes no ecossistema artificial a ser recuperado, enquanto a fração majoritária, 46 espécies, foi classificada na classe de mortalidade medianamente baixa (Tabela 1).

Uma taxa de mortalidade de $10 \%$ de mudas foi considerada referência por Almeida e Sánchez (2005) em projetos de revegetação em áreas mineradas no Estado de São Paulo, apesar de terem verificado taxa de $38 \%$ de mudas mortas. Segundo Piña-Rodrigues et al. (1997), até $20 \%$ de mortes em mudas pode ser considerada normal em projetos de revegetação de áreas mineradas. Em ambos os trabalhos, não se faz referência ao período de tempo considerado.

A sobrevivência e o crescimento em altura e diâmetro de seis espécies arbóreas (Inga marginata, Hymenaea stigonocarpa, Genipa americana, Couepia grandiflora, Tapirira guianensis e Kielmeyera lathrophytum) em substrato de uma cascalheira, no Distrito Federal, testadas por Silva e Corrêa (2008), indicaram que apenas 6,7\% das mudas de Kielmeyera lathrophytum sobreviveram ao final de duas estações chuvosas, enquanto as demais espécies apresentaram sobrevivência superior a 90\%.

\subsection{Crescimento em Diâmetro e Altura}

O crescimento das árvores é decorrente da atividade meristemática que resulta no alongamento de algumas estruturas anatômicas e no aumento do porte das raízes, troncos e galhos, com consequentes mudanças ao longo do tempo no peso, tamanho e forma das árvores; esse crescimento não é constante durante toda a vida de uma árvore (CHASSOT et al., 2011). Em muitas espécies climácicas, observou-se diminuição do incremento em diâmetro (ENCINAS et al., 2005).

O crescimento em diâmetro de árvores individuais pode ser expresso pelo incremento em diâmetro ou em área basal. Uma decisão a ser tomada na modelagem é em relação à variável resposta, ou seja, modelar o diâmetro futuro ou o incremento em diâmetro (CHASSOT et al., 2011). De acordo com Vanclay (1994), o aumento no diâmetro do tronco pode ser expresso como função de produção, a qual estima diâmetros futuros, ou como função de crescimento, que estima o incremento durante um período específico. Scolforo et al. (2008) observaram que nas 19 espécies analisadas em floresta semidecidual de Minas Gerais predomina a tendência de crescimento exponencial, deduzindo-se que uma possível explicação seria de que as populações não contariam na área com indivíduos próximos a completar o ciclo de crescimento; as demais espécies apresentaram trajetória retilínea de crescimento com várias possíveis explicações para esse padrão: (i) é provável que essas espécies nunca desacelerem seu crescimento, (ii) podem ser espécies imigrantes na área e que ainda não atingiram a fase final do ciclo de crescimento ou (iii) a variância das taxas de crescimento é tão alta que torna impossível detectar diferenças significativas nas taxas de crescimento entre as diferentes classes de diâmetro. Prosseguindo, aqueles autores informaram que nenhuma espécie apresentou trajetória de diâmetro sigmoidal, ou seja, com tendência a diminuir o crescimento com o aumento da idade. Concluíram que essa tendência era intrínseca àquelas espécies em que pelo menos alguns indivíduos se aproximaram do final do ciclo de crescimento quando o diâmetro passa a aumentar muito pouco.

O crescimento anual do diâmetro basal médio de 34 espécies ( $n \geq 20)$ dos reflorestamentos do platô Saracá, na FLONA de Saracá Taquera, avaliado por Salomão et al. (2006), permitiu concluir que o incremento periódico anual variou de 3,22 $\mathrm{cm}^{-1} \mathrm{ano}^{-1}$ (Senna multijuga) a $0,16 \mathrm{~cm} \mathrm{ano}^{-1}$ (Clarisia racemosa), média de 0,98 $\pm 0,74 \mathrm{~cm}$ ano $^{-1}$. Leão et al. (2005) retrataram o crescimento em diâmetro (DAP) de 29 espécies amazônicas plantadas em Tucuruí, PA, concluindo que no período de 15 anos o incremento periódico anual variou de 2,16 $\mathrm{cm} \mathrm{ano}^{-1}$ 
(Acromia aculeata) a 0,30 $\mathrm{cm} \mathrm{ano}^{-1}$ (Theobroma grandiflorum), com média geral de $0,95 \pm 0,49 \mathrm{~cm}$ ano $^{-1}$. Tonini et al. (2005) avaliaram quatro espécies florestais (andiroba, castanheira, ipê-roxo e jatobá) em programas de reflorestamentos e de sistemas agroflorestais em Roraima, concluindo que essas espécies apresentaram incrementos médios anuais em diâmetro superiores a $1 \mathrm{~cm}$.

Neste trabalho, no reflorestamento implantado em 1996 o incremento periódico anual do diâmetro basal (DAS) das 69 espécies analisadas, num período de 13 anos, variou de $2,50 \mathrm{~cm}^{\mathrm{ano}}{ }^{-1}$ (Sclerolobium paniculatum) a $0,01 \mathrm{~cm}^{\mathrm{ano}}{ }^{-1}$ (Spondias lutea), média de $0,48 \pm 0,41 \mathrm{~cm}^{\mathrm{ano}}{ }^{-1}$. A média do IPA do diâmetro basal das espécies deste trabalho foi praticamente a metade daquela estimada por Salomão et al. (2006) e que envolveu 34 espécies das áreas anuais de restauração do platô Saracá. A diminuição observada do IPA de quase $100 \%$ deste trabalho em relação àquele não pode ser explicada pelo baixo número de espécies do reflorestamento de 1996, uma vez que neste o número foi de 89 espécies (Tabela 2). O que provavelmente pode estar ocorrendo é que as espécies empregadas pela empresa desde 1981 até 1996 sejam mais características da floresta ombrófila densa submontana, uma vez que foi observado, na área de 1996, o uso de várias espécies das matas ciliares do rio Trombetas. A fertilização e calagem no plantio, a quantidade de solo superficial (terra-preta) espalhado superficialmente nas áreas de plantio e o tempo de "armazenamento" desse solo superficial desde a supressão da floresta, via corte raso, até o momento de espalhamento na área de plantio - que pode variar de meses a anos - muito certamente contribuíram para explicar essa alta discrepância entre incrementos observados em áreas distintas de plantios no mesmo platô da FLONA.

Nove espécies florestais amazônicas, em plantios com 11 anos de idade, foram avaliadas através do incremento médio anual (IMA) do diâmetro, por Souza et al. (2008), que concluíram que o maior incremento foi em Sclerolobium paniculatum "taxi branco" (2,0 $\left.\mathrm{cm} \mathrm{ano}^{-1}\right)$ e o menor em Dipteryx odorata 'cumaru' $\left(0,8 \mathrm{~cm} \mathrm{ano}^{-1}\right)$; com valores intermediários, foram observadas Hymenaea courbaril 'jatobá' e Carapa guianensis 'andiroba' (ambos com 1,5 cm ano-1), Swietenia macrophylla 'mogno' e Cedrela odorata 'cedro' (1,4 cm ano $\left.{ }^{-1}\right)$, Bertholletia excelsa 'castanheira', Copaifera multijuga 'copaíba' e Trattinickia burseraefolia 'breu sucuruba' $\left(1,2 \mathrm{~cm} \mathrm{ano}^{-1}\right)$. O resultado de Sclerolobium paniculatum obtido por esses autores e corroborado parcialmente (uma vez que $\mathrm{n}<10$ indivíduos) por este estudo indica que a espécie pode ser considerada de ótimo potencial para recuperação de áreas degradadas. Os autores desta pesquisa observaram recentemente que em alguns locais da FLONA, devido às inúmeras germinações de sementes da espécie nos taludes de tanques de rejeito e de estradas, a espécie tem tendência a apresentar características de planta dominante e, devido à sua alta densidade, poderá dificultar que outras espécies da floresta se desenvolvam nessas áreas.

Tapirira guianensis, Inga marginata e Genipa americana apresentaram excelentes resultados de sobrevivência e desenvolvimento (crescimento em diâmetro e altura) em área de lavra de areia em São Paulo, SP, de acordo com Silva e Corrêa (2008). Em dois projetos de revegetação em áreas mineradas de São Paulo, Almeida e Sánchez (2005) concluíram que aos 5 anos o crescimento em altura das mudas foi pouco vigoroso, com plantas que variaram de 0,7 a $5 \mathrm{~m}$; informaram ainda não haver estrato emergente, pois o manejo impediu o crescimento de qualquer outra espécie.

Neste trabalho, a aptidão ecológica da espécie foi analisada pelo comportamento da taxa de mortalidade e do incremento periódico anual do diâmetro basal e da altura ao longo de determinado período de tempo. As 89 espécies agrupadas em cinco classes de aptidão em relação ao ecossistema artificial formado pela restauração florestal de áreas de pós-lavra na Amazônia permitiram a conclusão de que, a se manterem as projeções de crescimento e mortalidade, cerca de 45 espécies, praticamente a metade, não deveriam ser recomendadas para plantio, por apresentarem baixa aptidão ou não serem aptas naquele momento (ano 0) e, sim, talvez após o desenvolvimento de sombra ao nível do solo (a partir do ano 3). Uma questão que deve ser analisada é se a quantidade de solo superficial (terra-preta) espalhada nas áreas de plantio estaria adequada para o desenvolvimento dessas espécies.

\subsection{Análise das práticas de caráter edáfico}

A mineração de superfície provoca grandes impactos no solo e na topografia do local através da erosão e da sedimentação que atingem seu máximo impacto sobre os recursos hídricos a partir do início das atividades até pelo menos seis meses depois das operações (CURTIS, 1973). O depauperamento e o caráter tóxico dos solos

Revista Árvore, Viçosa-MG, v.38, n.1, p.1-24, 2014 
também precisam ser corrigidos para que o local alterado se torne produtivo e não seja prejudicial ao meio ambiente. A única maneira de mitigar a maior parte desses impactos negativos é através do restabelecimento de uma cobertura vegetal perene sobre o local modificado. Thompson e Hutnik (1972) citaram alguns problemas intrínsecos a esses solos: a) instabilidade, b) textura inadequada, c) altas temperaturas diurnas na camada superficial e d) características químicas e biológicas desfavoráveis dos solos remanescentes. Prevendo o estabelecimento de uma cobertura florestal perene como a melhor solução para recuperação de áreas mineradas, é necessário proceder ao preparo do local em que serão plantadas as mudas.

\subsubsection{Incorporação de solo superficial na área a restaurar}

A mineração de superfície exige a supressão total da vegetação e da capa superior do solo ('terra preta') existentes sobre o minério. Essa capa de solo, enriquecida com material orgânico, é deslocado para qualquer posição, o que, muitas vezes, favorece sua perda, causada pela ação da erosão hídrica. A restauração da paisagem florestal nas áreas submetidas à lavra é feita atendendo a dois pressupostos básicos e indispensáveis para o sucesso da operação: a facilitação dos processos da regeneração natural, através da reincorporação do solo superficial (IBAMA, 1990; SALOMÃO et al., 2007) e o plantio de árvores e palmeiras regionais, via reflorestamento (SALOMÃO et al., 2002).

Farmer et al. (1976) fizeram importante estudo sobre a revegetação dos restos ácidos provenientes da mineração de cobre-cobalto, concluindo que a armazenagem e a posterior redistribuição da capa superior do solo e da camada imediatamente inferior (até aproximadamente 20,5 cm de profundidade), em conjunto com um programa de fertilização, foram mais eficientes em estimular o revestimento vegetal do local.

Segundo O. H. Knowles (comunicação pessoal, 2006), havia recomendação da empresa mineradora para que se raspasse uma camada de 20-25 cm de solo superficial nas áreas a serem lavradas - esse volume consistiria no solo superficial a ser incorporado nas áreas anuais de plantios florestais. Esse solo superficial é separado à parte quando do preparo da área para retirada da bauxita, sendo posteriormente incorporado àquelas áreas onde já fora processada a lavra e que deveriam ser restauradas após a lavra da bauxita. Deve-se ressaltar que o ambiente artificial formado após a lavra e que deveria ser restaurado se encontrava no extremo de degradação ambiental, pois todas as propriedades físicas, químicas, biológicas e ecológicas do solo foram drasticamente alteradas ou destruídas pelas atividades decorrentes da lavra do minério. De acordo com Knowles (1992), em 1985 a empresa passou a adotar a prática de reincorporação superficial do solo orgânico ('terrapreta') nas áreas anuais de plantios florestais, formando uma camada de aproximadamente $11 \mathrm{~cm}$ de espessura sobre o estéril, cuja profundidade pode atingir 10-15 m.

Vários autores têm sugerido normas para armazenamento de solos superficiais. Segundo Tyson (1979), o ideal seria removê-los e armazená-los misturados com a vegetação do mesmo local, convertida mecanicamente em cobertura morta. De acordo com Geiser e Oliveira (1977), o solo pode ser amontoado em camadas de terra de até 1,5 m de altura e de 3 $4 \mathrm{~m}$ de largura, com qualquer comprimento. De preferência, o local deve ser plano e protegido das enxurradas e da erosão, devendo-se evitar a compactação do solo durante a operação de armazenamento. Também, o solo armazenado deveria ser protegido dos raios solares com uma cobertura de palha. Não se deve armazenar solos muito úmidos, nem fazê-lo em época de chuva (GEISER; OLIVEIRA, 1977). Os solos compactados durante mais de um ano em grandes montões perdem nutrientes e microrganismos (CANADÁ, 1975).

Em geral, os estudos sobre o tratamento de solos minerados recomendam a aplicação de uma cobertura morta para facilitar o estabelecimento da vegetação (COOK et al., 1974; SANDOVAL et al., 1973; SUTTON, 1970); o material utilizado pode ser palhas, cascas desfibradas de árvores, folhas, cavacos de madeira ou outro material orgânico. A vegetação removida do local a ser minerado, por exemplo, pode fornecer material para ser convertido em cobertura morta. Tyson (1979) concluiu que o sucesso da cobertura morta depende do uso da própria vegetação do local em combinação com o solo original. Também, verificou, na recuperação dos cortes de estradas, que o uso de fertilizantes não tornou a cobertura morta mais efetiva no processo da regeneração natural.

A acidez dos solos remanescentes das minerações inibe o estabelecimento de vegetação no processo de restauração. A acidez influi na disponibilidade de nutrientes e nos processos biológicos das plantas (BERG, 1965, 1976). Plass (1969) verificou que são poucas as espécies herbáceas ou arbóreas capazes 
de sobreviver em solos ácidos com pH entre 3,5 e 4,0 e que quase nenhuma espécie sobrevive em solos com pH inferior a 3,5. O calcário é frequentemente utilizado para corrigir problemas edáficos provenientes da alta acidez. Farmer et al. (1976) informaram que a acidez, embora corrigida inicialmente, frequentemente retorna a um alto nível.

\subsubsection{Escarificação do solo}

Alguns dos efeitos da escarificação superficial do solo são bem conhecidos: a) fornece leito e refúgio para as sementes, b) abre solos compactados para facilitar a infiltração hídrica e c) facilita a utilização de nutrientes e oxigênio pelas plantas. A escarificação feita por arados comuns pode apresentar problemas: a) alcançar pouca profundidade e b) danificar o arado, quando em solos rochosos, o que é muito comum em locais minerados (BROWN, 1977).

Aldon e Garcia (1972) e Aldon (1976) estudaram os efeitos da escarificação profunda em terreno semiárido, usando um aparelho especial, puxado por um trator, contendo dois "dentes" com 2,2 m entre si, os quais cortavam sulcos de $71 \mathrm{~cm}$ de profundidade e $10 \mathrm{~cm}$ de largura. Duas chapas, com a configuração de um triângulo e montadas na parte superior dos dentes, abriram mais ainda a parte superior dos sulcos, deixando-os com aproximadamente $38 \mathrm{~cm}$ de largura. Verificaram que a escarificação profunda reduziu em $85 \%$ o escoamento de água e, em 31\%, a erosão, medidos três anos após a aplicação do tratamento.

No processo de preparo do solo empregado na área estudada, o solo superficial cai dentro das linhas (no sulco), o que é interessante e desejável por favorecer com matéria orgânica e água o estabelecimento da futura muda ali plantada. Essa operação deve ser feita no fim do verão (outubro-novembro-dezembro), enquanto o solo ainda está seco, para que as primeiras chuvas de janeiro possam levar mais solo superficial para os sulcos (linhas de plantio) e, em fevereiro, tenha início o plantio florestal. A drenagem nas áreas de plantios era excelente, pois a camada de solo estéril chega a até $12 \mathrm{~m}$ de profundidade. Certamente, a textura, estrutura e mineralogia do substrato também interferem na drenagem.

A escarificação é prática silvicultural que mostrou desempenhar papel importante no estabelecimento das árvores nas áreas de restauração. Tal procedimento, além de diminuir a compactação nas linhas de plantio, promove a incorporação profunda de matéria orgânica, que pode apresentar textura arenosa, no solo subsuperficial, facilitando e estimulando, pela maior oferta de nutrientes e água nas camadas mais profundas, o desenvolvimento radicular (FERRAZ, 1991). Todavia, Salomão et al. (2007) alertaram que a compactação produzida pelas máquinas durante a sistematização do terreno para plantio não deve ser a ponto de produzir estrangulamento que venha impedir o crescimento do sistema radicular. Alertaram, também, que certa compactação favoreceria a retenção de água, que é vital para as plantas no período seco.

\section{CONCLUSÃO}

Dezessete espécies apresentaram mortalidade excepcionalmente baixa no período de 13 anos de monitoramento, no entanto outras 20 tiveram 100\% de mortalidade; aquelas devem ser priorizadas e estas, descartadas doravante na restauração florestal de áreas mineradas.

O número elevado de espécies com altas taxas de mortalidade pode indicar que o estágio sucessional dessas plantas não esteja sendo observado e, a se confirmar, deverão ser feitos ajustes no tempo de plantio dessas espécies.

Praticamente a metade das 89 espécies selecionadas não deveria ser recomendada doravante para plantio, por elas apresentarem baixa aptidão ecológica: baixo crescimento do diâmetro e da altura e altas taxas de mortalidade.

As espécies-chave da floresta primária que recobriam originalmente as áreas mineradas devem ser testadas nos futuros plantios, visando a uma melhor estrutura da nova floresta a ser restaurada.

As práticas de caráter edáfico devem ser revistas por apresentarem indícios de estarem influenciando fortemente a mortalidade e desenvolvimento das árvores plantadas nas áreas de restauração, sobretudo no que se relaciona ao tempo de estocagem e à quantidade de top soil a ser espalhada superficialmente nas áreas de restauração florestal.

\section{REFERÊNCIAS}

ALMEIDA, R. O. P. O.; SÁNCHEZ, L. E. Revegetação de áreas de mineração: critérios de monitoramento e avaliação do desempenho.

Revista Árvore, v.29, n.1, p.47-54. 2005. 
CAMPOS, J. C. C.; LEITE, H. G. Mensuração florestal: perguntas e respostas. 2.ed. Viçosa, MG: Universidade Federal de Viçosa, 2006. 470p.

CANADÁ. Ministry of Natural Resources. Vegetation for the rehabilitation of pits and quarries. Ontario, Division of Forests, 1975. 38p.

CHAMBERS, J. Q.; HIGUCHI, N.; SCHIMEL, J. Ancient trees in Amazonia. Nature, v. 391, n.8 p.135-136, 1998.

CHASSOT, T. et al. Modelos de crescimento em diâmetro de árvores individuais de Araucaria angustifolia (Bertol.) Kuntze em floresta ombrófila mista. Ciência Florestal, v.21, n.2, p.303-313, 2011.

CLARK, D. A.; CLARK, D. B. Climate-induced annual variation in canopy tree growth in Costa Rica tropical rain forest. Journal of Ecology, v.82, p.865-872, 1994.

CURTIS, W. R. Effects of strip-mining on the hydrology of small mountain watersheds in Appalachia. in: HUTNIK, R. J.; DAVIS, G. Ecology and reclamation of devastated land. New York: Gordon and Breach, 1973. v. 1. p. $145-157$.

ENCINAS, J. I.; SILVA, G. F.; PINTO, J. R. R. Idade e crescimento das árvores. Comunicações Técnicas Florestais, v.7, n.1, dez. 2005.

FARMER, E. E.; RICHARDSON, B. Z.; BROWN, R. W. Revegetation of acid mining wastes in Central Idaho. Ogden, Utah, U.S. Department of Agriculture, Forest Service, 1976. 17 p. (Research Paper).

HEINSDIJK, D. A distribuição dos diâmetros nas florestas brasileiras. Ministério da Agricultura, Departamento de Recursos Naturais Renováveis, Setor de Inventários Florestais, 1965. p.56. (Boletim, 11)

INSTITUTO BRASILEIRO DO MEIOAMBIENTE E DOS RECURSOS NATURAIS RENOVÁVEIS IBAMA. Manual de recuperação de áreas degradadas pela mineração: técnicas de revegetação. Universidade do Texas, 1990. 96p.

Revista Árvore, Viçosa-MG, v.38, n.1, p.1-24, 2014
INSTITUTO NACIONAL DE METEOROLOGIA (INMET) Disponível em: <http://

www.inmet.gov.br/html/clima/mapas/?mapa=inso $>$. Acesso em: 29 de maio de 2012.

LAMB, D.; GILMOUR, D. Issues in forest conservation. Rehabilitation and restoration of degraded forests. International Union for Conservation of Nature and Natural Resources (IUCN) and The World Wide Fund for Nature (WWF), 2003. 122p.

LAPA, R. P. A bauxita e o rejeito da bauxita. In: BOZELLI, R. L.; ESTEVES, F. A.; ROLAND, F. (Ed). Lago Batata: impacto e recuperação de um Ecossistema Amazônico. Rio de Janeiro: IBUFRJ/SBL, 2000. p.27-35.

LEÃO, N. V. M. et al. Ilha de germoplama de Tucuruí: uma reserva da biodiversidade para o futuro. Brasília: Eletronorte. 2005. 232p.

MORAES, V. H. F. Periodicidade de crescimento do tronco em árvores da floresta amazônica. Pesquisa Agropecuária Brasileira, v.5, p.315-320, 1970.

OLIVEIRA, L. C.; SILVA, J. N. M. Dinâmica de uma floresta secundária no Planalto de Belterra, Santarém - Pará. In: SIMPÓSIO/WORKSHOP INTERNACIONAL MANEJO E REABILITAÇÃO DE ÁREAS DEGRADADAS E FLORESTAS SECUNDÁRIAS NAAMAZÔNIA, 1995, Santarém. Anais... Santarém: USDA - Forest Service, 1995. p.122-135.

PEEL, M. C.; FINLAYSON, B. L.; MCMAHON, T. A. Updated world map of the K" oppen-Geiger climate classification. Hydrology and Earth System Sciences, v.11, p.1633-1644, 2007.

PIÑA-RODRIGUES, F. C. M.; LOPES, L.; BLOOMFIELD, V. K. Análise do desenvolvimento de espécies arbóreas da Mata Atlântica em sistema de plantio adensado para a revegetação de áreas degradadas em encosta, no entorno do Parque Estadual do Desengano (RJ). In: SIMPÓSIO NACIONAL DE RECUPERAÇÃO DE ÁREAS DEGRADADAS III SINRAD, 1997, Ouro Preto. Anais... Curitiba: Sociedade Brasileira de Recuperação de Áreas Degradadas/Sobrade/Universidade Federal de Viçosa/UFV, 1997. p.283-291. 
PIRES, J. M. Aspectos ecológicos da floresta amazônica. In: CONGRESSO BRASILEIRO DE FLORESTAS TROPICAIS, 2., 1976, Mossoró. Anais... Mossoró: 1976. p.30-53. (Coleção Mossoroense, 65)

RADAMBRASIL. Projeto. Folha SA.21 Santarém: 1976. v.10. p.310-414.

REAY, S. D.; NORTON, D. A. Assessing the success of restoration plantings in a temperate New Zealand forest. Restoration Ecology, v.7, p.298-308, 1999.

RODRIGUES, R. R.; GANDOLFI, S. Conceitos, tendências e ações para a recuperação de florestas ciliares. In: RODRIGUES, R. R.; LEITÃO FILHO, H. F. Matas ciliares: conservação e recuperação. São Paulo: USP/FAPESP, 2000. p.235-248.

SALOMÃO, R. P.; MATOS, A. H.; ROSA, N. A. Dinâmica de reflorestamentos visando a restauração da paisagem florestal em áreas de mineração na Amazônia. Boletim do Museu Paranaense Emílio Goeldi, Série Botânica, v.18, n.1, p.157-94. 2002.

SALOMÃO, R. P.; MATOS, A. H.; ROSA, N. A. Dinâmica do sub-bosque e do estrato arbóreo de floresta tropical primária fragmentada na Amazônia oriental. Acta Amazonica, v.32, p.387-419, 2002.

SALOMÃO, R. P.; ROSA, N. A.; CASTILHO, A.; MORAIS, J. A. C. Castanheira-do-brasil recuperando áreas degradadas e provendo alimento e renda para comunidades da Amazônia

Setentrional. Boletim do Museu Paraense Emílio Goeldi. Ciências Naturais, v.1, n.2, p.65-78, 2006.

SALOMÃO, R. P.; ROSA, N. A.; MORAIS, K. A. C. Dinâmica da regeneração natural de árvores em áreas mineradas da Amazônia. Boletim do Museu Paraense Emílio Goeldi. Ciências Naturais, v.2, n.1, p.85-139, 2007.

SALOMÃO, R. P.; SANTANA, A. C.; BRIENZA JÚNIOR, S. Análise da florística e estrutura de floresta primária visando a seleção de espécieschave, através de análise multivariada, para a restauração de áreas mineradas em unidades de conservação. Revista Árvore, v.36, n.6, p.989-1007, 2012.
SCHEEREN, L. W. et al. Crescimento do louropardo, Cordia trichotoma (Vell.) Arrab. ex Steud., na depressão central do estado do Rio Grande do Sul. Ciência Florestal, v. 12, n. 2, p. 169-176, 2002.

SCOLFORO, J. R. et al. Trajetórias de crescimento de espécies de florestas semideciduais. In: SCOLFORO, J. R.; MELO, J. M.; SILVA, C. P. C. (Ed.) Inventário florestal de Minas Gerais: floresta estacional semidecidual e ombrófila - florística, estrutura, diversidade, similaridade, distribuição diamétrica e de altura, volumetria, tendências de crescimento e áreas para manejo florestal. Lavras: Universidade Federal de Lavras, 2008. p.633-647.

SOCIETY FOR ECOLOGIAL RESTORATION SER. Princípios da SER International sobre a restauração ecológica, 2004. SER and Tucson: Society for Ecological Restoration International. Disponível em: < (http:// www.ser.org)> Acesso em: 4 de out. de 2010 .

SILVA, L. C. R.; CORRÊA, R. S. Sobrevivência e crescimento de seis espécies arbóreas submetidas a quatro tratamentos em área minerada no cerrado. Revista Árvore, v.32, n.4, p.731-740. 2008.

SOUZA, C. R. et al. Desempenho de espécies florestais para uso múltiplo na Amazônia.

Scientia Forestalis, v.36, n.77, p.7-15, 2008.

SUDAM. Levantamentos florestais realizados pela Missão FAO na Amazônia. Belém:

Superintendência do Desenvolvimento da Amazônia, Divisão de Documentação, 1974. 2v.

THOMPSON, D. N.; HUTNIK, R. J. Environmental characteristics affecting plant growth on deepmine coal refuse banks. Pennsylvania State University School of Forestry Research Briefs, v.6, n.2, p.22-25, 1972.

TONINI, H.; ARCO-VERDE, M. F.; SÁ, S. P. P. Dendrometria de espécies nativas em plantios homogêneos no estado de Roraima - andiroba (Carapa guianensis Aubl), castanha-do-Brasil (Bertholletia excelsa Bonpl.), ipê-roxo (Tabebuia avellanedae Lorentz ex Griseb) e jatobá (Hymenaea courbaril L.). Acta Amazônica, v.35, n.3, p.353-362, 2005.

Revista Árvore, Viçosa-MG, v.38, n.1, p.1-24, 2014 
VANCLAY, J. K. Modelling forest growth and yield: applications to mixed tropical forest. Wallingford: Cab International, 1994. 312p.

VEILLON, J. P.; KONRAD, V. W.; GARCIA, N. Estudio de la masa forestal y su dinamismo en parcelas de diferentes tipos ecológicos de bosques naturales de las tierras bajas venezolanas. Revista Forestal

Venezuelana, v.19, n.26, p.73-106, 1976.
VIEIRA, I. C. G. et al. Bases técnicas e referenciais para o Programa de Restauração Florestal do Pará: Um Bilhão de Árvores para a Amazônia. Pará Desenvolvimento, v.2, p.9-103, 2009.

VIEIRA, S. A. Mudanças globais e taxa de crescimento arbóreo na Amazônia. 133f. 2003. Tese (Doutorado em Ciências) -

Universidade de São Paulo, Centro de Energia Nuclear na Agricultura, Área de Concentração: Energia Nuclear na Agricultura, 2003. 